\title{
Simulating Ocean and Tidal Current Power Plants with Homer
}

\author{
Andrea Fischer ${ }^{1}$, Jones S. Silva ${ }^{2}$, Alexandre Beluco², Luiz Emílio B. Almeida² \\ ${ }^{1}$ Instituto Federal Sul Riograndense (IFSUL), Pelotas, RS, Brazil \\ ${ }^{2}$ Instituto de Pesquisas Hidráulicas, Universidade Federal do Rio Grande do Sul (UFRGS), Porto Alegre, Brazil \\ Email: andrea@pelotas.ifsul.edu.br, joneswsilva@gmail.com, albeluco@iph.ufrgs.br
}

Received 20 April 2015; accepted 11 July 2015; published 14 July 2015

Copyright (C) 2015 by authors and Scientific Research Publishing Inc.

This work is licensed under the Creative Commons Attribution International License (CC BY).

http://creativecommons.org/licenses/by/4.0/

\begin{abstract}
The oceans can provide us with several direct sources of renewable energy, such as wave energy, energy from currents and energy in thermal gradients among other energy resources. The uses of these resources have not yet reached technical and economic maturity, but they have experienced significant advances in recent years. In this process, tools for feasibility analysis of hybrid systems including specific power plants are important. This article is dedicated to the feasibility study of hybrid systems containing power plants based on the energy of ocean and tidal currents. The software currently available for feasibility studies do not present specific models already developed for the simulation of this kind of power plants. Thus, this technical note shows how Homer software (Legacy version) can be used to conduct this type of study in pre-feasibility level. This article also presents a case study in which Homer is applied, focused only on Homer adaptation but without exhausting the subject, showing a feasibility window that would include current power plants with certain cost and efficiency in an existing PV wind biodiesel hybrid system.
\end{abstract}

\section{Keywords}

Ocean Energy, Ocean Current Energy, Tidal Current Energy, Computational Simulation, Feasibility Study, Software Homer

\section{Introduction}

The oceans can provide some very interesting sources of renewable energy, such as wave energy, ocean and tidal currents energy and energy in thermal gradients among others. These energy sources have not yet achieved technical and economic maturity, but they have shown significant progress in recent years. There are some power plants already installed capable of providing reasonable energy supplies, demonstrating the viability of the use of these renewable resources. 
This technical note is dedicated to the energy from ocean and tidal currents, presenting in many continental shelves. The conversion of this kind of energy is very similar to the conversion of wind energy with the advantage that water has a density about 800 times greater than the density of air.

There are various configurations for current energy conversion devices [1], some of them are similar to wind turbines (as is the case of horizontal axis turbine [2]) while others are different (as is the case of oscillating hydrofoil [3]). Structures for the current energy conversion submerged are associated with structures for conversion of wind energy, out of sea water, consisting of an increasingly common configuration.

To the extent that each energy source has its own characteristics, it is necessary to know how it can be inserted in hybrid energy systems. A technical and economic "feasibility window" must be known in order to determine with greater accuracy the target to be achieved by technology developers and managers of energy resources.

Homer software [4] is a software that performs hybrid systems simulations in order to provide an optimal combination of components. The focuses of Homer are the small power systems containing models of energy resources that are already technically and economically mature. Homer may be adapted to simulate current power plants and allowing the determination of a viability window appropriate for the use of current energy.

Homer is a software fast to be programmed, simple to be learned [5] and very friendly with regard to the evaluation of results. The version Legacy is currently available free of charge and is sufficient for most applications related to hybrid systems with micro hydro power, wind energy and PV modules contributions, with batteries and other storage devices, including also the adaptation discussed in this technical note.

This technical note shows how Homer can be used to simulate ocean and tidal current power plants and describes a case study in southern Brazil in which the inclusion of a current power plant in a wind photovoltaic biodiesel hybrid system is simulated. As suggested in this work, Homer can be used for any design of equipment for energy conversion, with the focus always on the evaluation of the economic feasibility. The case study is not exhaustive and only shows some results.

\section{Power from Ocean and Tidal Currents}

The power $P_{a, \text { cur }}\left[\mathrm{W} / \mathrm{m}^{2}\right]$ available per unit cross sectional area of the water mass in motion is given by Equation (1) [6], where $C_{P, \text { cur }}[1]$ is the power coefficient, $\rho_{s w}\left[\mathrm{~kg} / \mathrm{m}^{3}\right]$ is the density of sea water and $V_{\text {cur }}[\mathrm{m} / \mathrm{s}]$ is the average current velocity.

$$
P_{a, \text { cur }}=\frac{1}{2} C_{P, \text { cur }} \rho_{\text {sw }} V_{\text {cur }}^{3}
$$

The available energy in ocean currents is presented in a more thoroughly manner by reference [7], which also discusses the estimation of energetic potential. This equation is very similar to the equation for wind potential and, in fact, these two energy resources are quite similar.

For a real power plant consisting of a set of machines with a total area $A\left[\mathrm{~m}^{2}\right]$ perpendicular to the flow direction and an overall performance of the plant equal to $\eta_{c u r}[1]$, the power $P_{c u r}[\mathrm{~W}]$ which may be available will be given by Equation (2).

$$
P_{\text {cur }}=P_{a, \text { cur }} A_{\text {cur }} \eta_{\text {cur }}
$$

Regarding the area $A$, conversion equipment with a design similar to horizontal axis turbines offers a circular area perpendicular to the flow. Equipment based as an example on the interaction of a hydrofoil with the flow, as is the case of oscillating hydrofoils, will provide a rectangular area. Some devices with vertical axis or with some types of concentrators may involve somewhat more complex areas.

Regarding the efficiency, most devices currently in development involve performances between $30 \%$ and 40\%. [1]-[7] In this sense, to get a better relation between the total energy available and the energy obtained with the conversion device, the limitations imposed by Betz theorem should also be considered, as well as the limitations imposed by the interaction of the plant with the energy system, which can be evaluated by the capacity factor.

Substituting (1) into (2), the power $P_{c u r}$ can be written as shown in (3).

$$
P_{\text {cur }}=\frac{1}{2} C_{P, \text { cur }} \rho_{\text {sw }} V_{\text {cur }}^{3} A_{\text {cur }} \eta_{\text {cur }}
$$


This equation will be used to build the model for the description of ocean and tidal current power plants.

\section{Software Homer}

Software Homer [4], The Micropower Optimization Model, was developed by National Renewable Energy Laboratory (NREL), U.S. Department of Energy, and is available for universal access in its version Legacy. Homer simulates a system for power generation usually over a period of 25 years at intervals of 60 minutes, presenting the results for one of the simulated years. [8] [9]

Homer includes models for simulation of micro hydro power plants, wind turbines, photovoltaic modules and fuel based generators. The software must be supplied with technical specifications of the genera to requipments, the availability of energy resources and characteristics of consumed fuels. Homer also includes models of various types of loads and alternatives for energy storage.

Figure 1 shows the components available for the simulation of energy systems. Homer simulate systems with multiple generators in parallel, with up to ten different designs of generator sets, up to ten different models of batteries. Homer can also simulate the grid connection, including rules for forecasting, when required by the operator of the electric system, and compare situations with and without connection to the grid.

Homer allows the user to identify the required components for a particular energy system. Furthermore, the user presents a set of values for the optimization variables (such as the number of wind turbines or the number of PV modules) and sensitivity variables (such as wind speed or the price of liter of diesel). Homer simulates a system for all sensitivity inputs, identifying the best combination of optimization variables.

The intention of this work is the simulation of ocean and tidal current power plants, not currently contemplated by Homer. In the absence of specific models, then the solution will be obtained improvising with some of the available models. Obviously, there will be restrictions on this practice, which should always be carefully evaluated not to exceed the limitations of the models and not lead to invalid results.

The most appropriate choice for the characteristics of the equipment is the model of wind turbines. The equations for the models of wind turbines and current power plants are very similar. In case of systems including wind energy, the model of hydroelectric power plants will be used. It should be emphasized however that the parameters of these models, like cross sectional area of wind turbines or available head at a micro hydro power plant, in the case of simulation of a current power plant, lose their original meaning and become new model parameters.

The great difference between these models is that wind turbines typically operate with capacity factors between $30 \%$ and $35 \%$, while hydroelectric power plants operate with much higher capacity factors, close to $90 \%$, mainly due to the variability of energy resources. Ocean currents present lower variability when compared to wind resources, but does not allow the capacity factors obtained with hydroelectric plants.

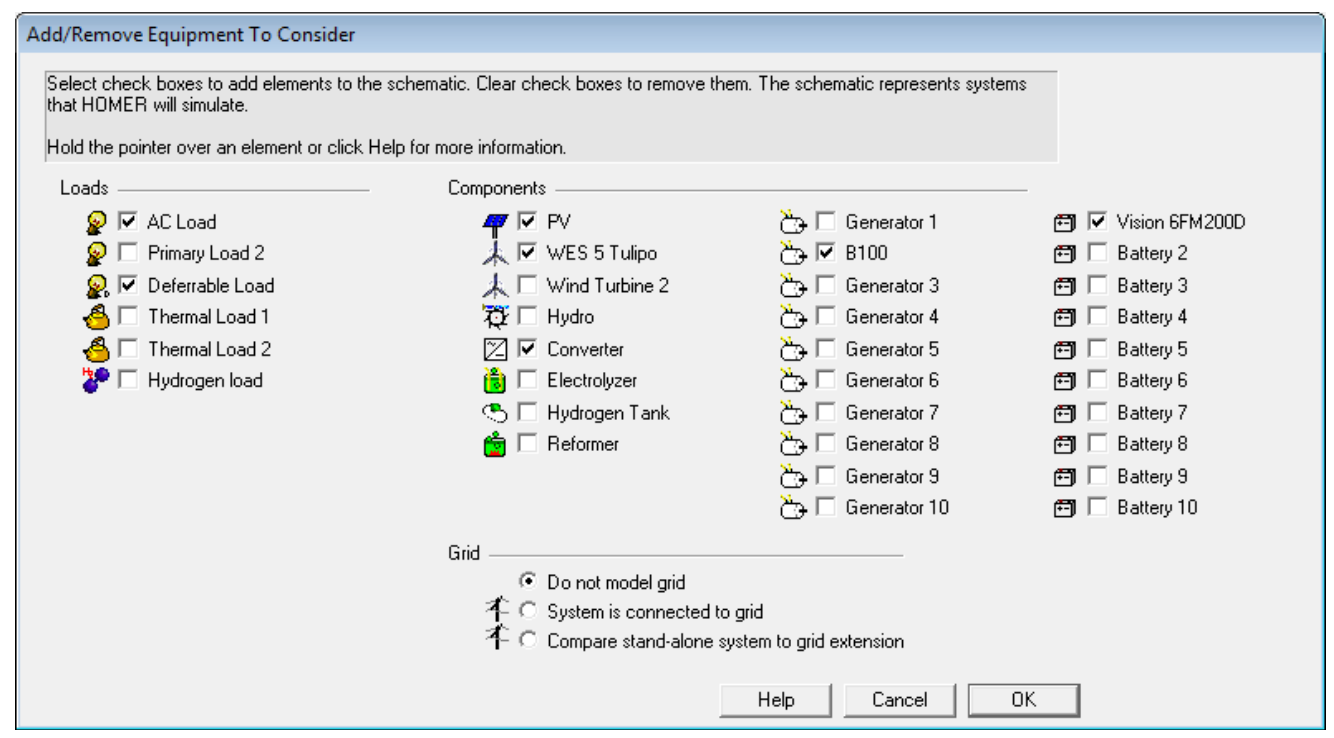

Figure 1. Alternatives offered by HOMER for simulation of hybrid energy systems. 


\section{Simulating Systems without Wind Energy Contribution}

The most appropriate choice is the model of wind turbines. Then, for systems without contribution of wind power, the wind turbine model can be used to simulate a current power plant. This limitation is due to the fact that Homer is suitable for optimization of micro systems and therefore does not accept different wind resources, as might occur for larger systems. The current energy resource presents values of capacity factor higher than those presented by wind power, but the equations are completely equivalent.

The power $P_{a, w}\left[\mathrm{~W} / \mathrm{m}^{2}\right]$ available per unit cross sectional area of the water mass in motion is given by Equation (4) [6], similar to Equation (1), where $C_{P, w}[1]$ is the power coefficient, $\rho_{\text {air }}\left[\mathrm{kg} / \mathrm{m}^{3}\right]$ is the density of air and $V_{w}[\mathrm{~m} / \mathrm{s}]$ is the average current velocity.

$$
P_{a, w}=\frac{1}{2} C_{P, w} \rho_{a i r} V_{w}^{3}
$$

For a real power plant consisting of a set of machines with a total area $A\left[\mathrm{~m}^{2}\right]$ and an overall performance of the plant equal to $\eta_{w}[1]$, the power $P_{w}[\mathrm{~W}]$ which may be available will be given by equation (5).This equation can obviously also be applied to each of the energy conversion devices independently.

$$
P_{w}=P_{a, w} A_{w} \eta_{w}
$$

Substituting (4) into (5), the power $P_{c u r}$ can be written as shown in (6).

$$
P_{w}=\frac{1}{2} C_{P, w} \rho_{a i r} V_{w}^{3} A_{w} \eta_{w}
$$

Figure 2 shows the information that must be provided on the wind turbines for the simulations. Information about the turbine being considered appears in the upper left corner. The turbine can be selected and even new turbines can be inserted. The power curve appears to the right. In the same frame, information about costs, lifetime and about installation height can be inserted. The column that appears below "sizes to consider" consists of optimization values related to the number of devices. In brackets are the sensitivity inputs.

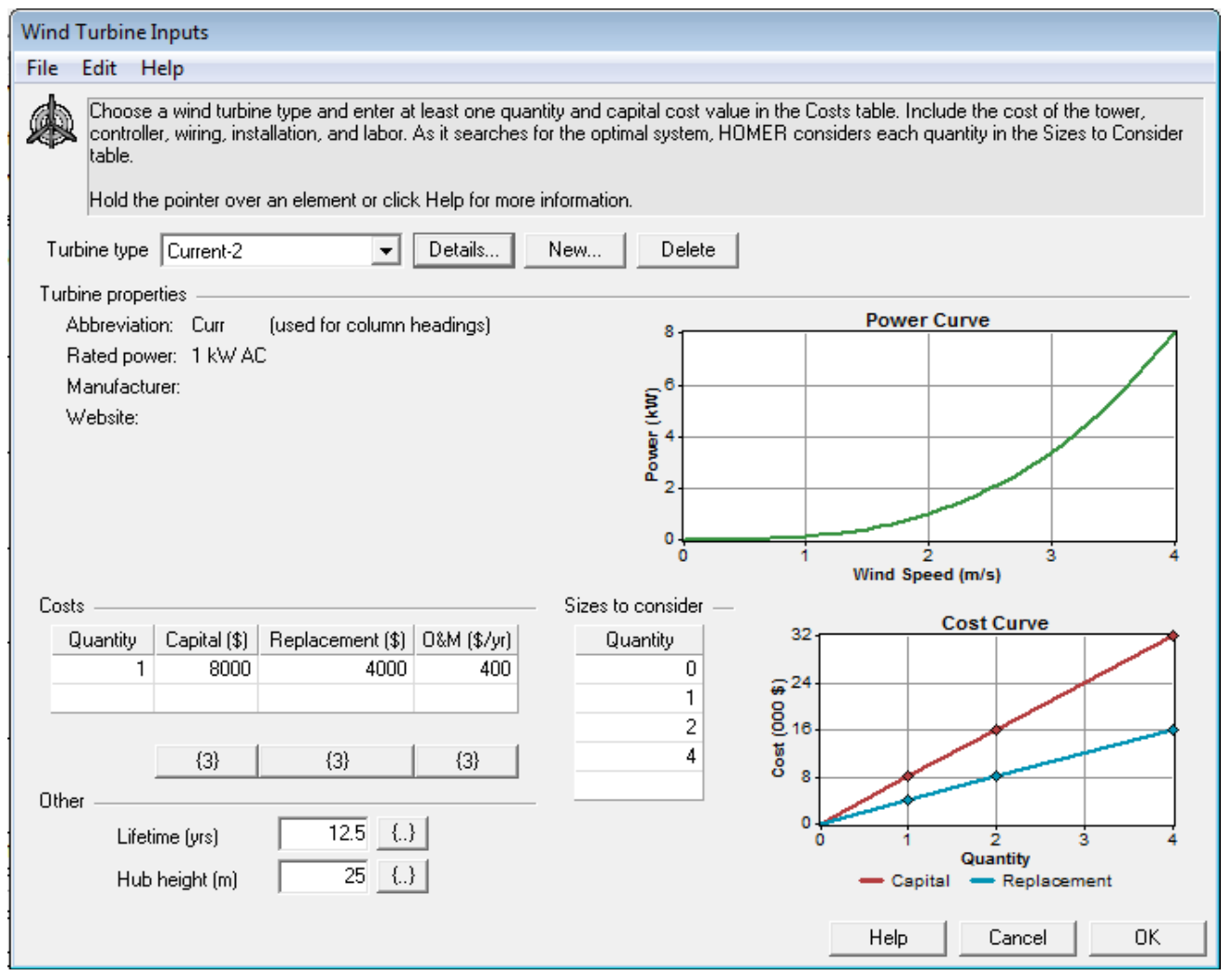

Figure 2. Parameters for the HOMER's model of a wind turbine. 
Figure 3 shows the box that is accessed by clicking "New" in the box shown in Figure 2. Performance data must be entered relating only to wind speed and power output. Other important information such as the rated power and the turbine operates on AC or DC must be inserted in the upper left corner of the form. The information entered can be found by clicking "Detais" in the box of Figure 2.

Equation (7) shows how Homer gets the data to the model for wind turbines. Simply enter the function that relates wind speed to power generated. The model for turbine currents can be entered by clicking "new" in the window that appears in Figure 2 and entering the corresponding function between current speed and generated power. Clearly, information about efficiency is implicit in the data entered in the spreadsheet.

$$
P_{w}=\kappa_{w} V_{w}^{3}
$$

Equation (8) shows the value for the constant that relates the wind speed and generated power. This constant relates the values of speed and power inserted into the spreadsheet in Figure 3.

$$
\kappa_{w}=\frac{1}{2} C_{P, w} \rho_{a i r} A_{w} \eta_{w}
$$

For the case of current power plant, the Equations (9) and (10) show respectively the corresponding values for the relationship between current speed and generated power and the constant that relates them.

$$
\begin{gathered}
P_{\text {cur }}=\kappa_{\text {cur }} V_{\text {cur }}^{3} \\
\kappa_{\text {cur }}=\frac{1}{2} C_{P, \text { cur }} \rho_{\text {sw }} A_{\text {cur }} \eta_{\text {cur }}
\end{gathered}
$$

For the case of plants with different dimensions and with different efficiencies it will need to enter new turbines in Homer. This process should always be started by clicking "New" in the windows that appears in Figure 2 (shown in Figure 3). Homer accepts data up to two different turbines, but (as it was mentioned above) related to only one set of data. The number of turbines and their costs must be entered in the window shown in Figure 2 .

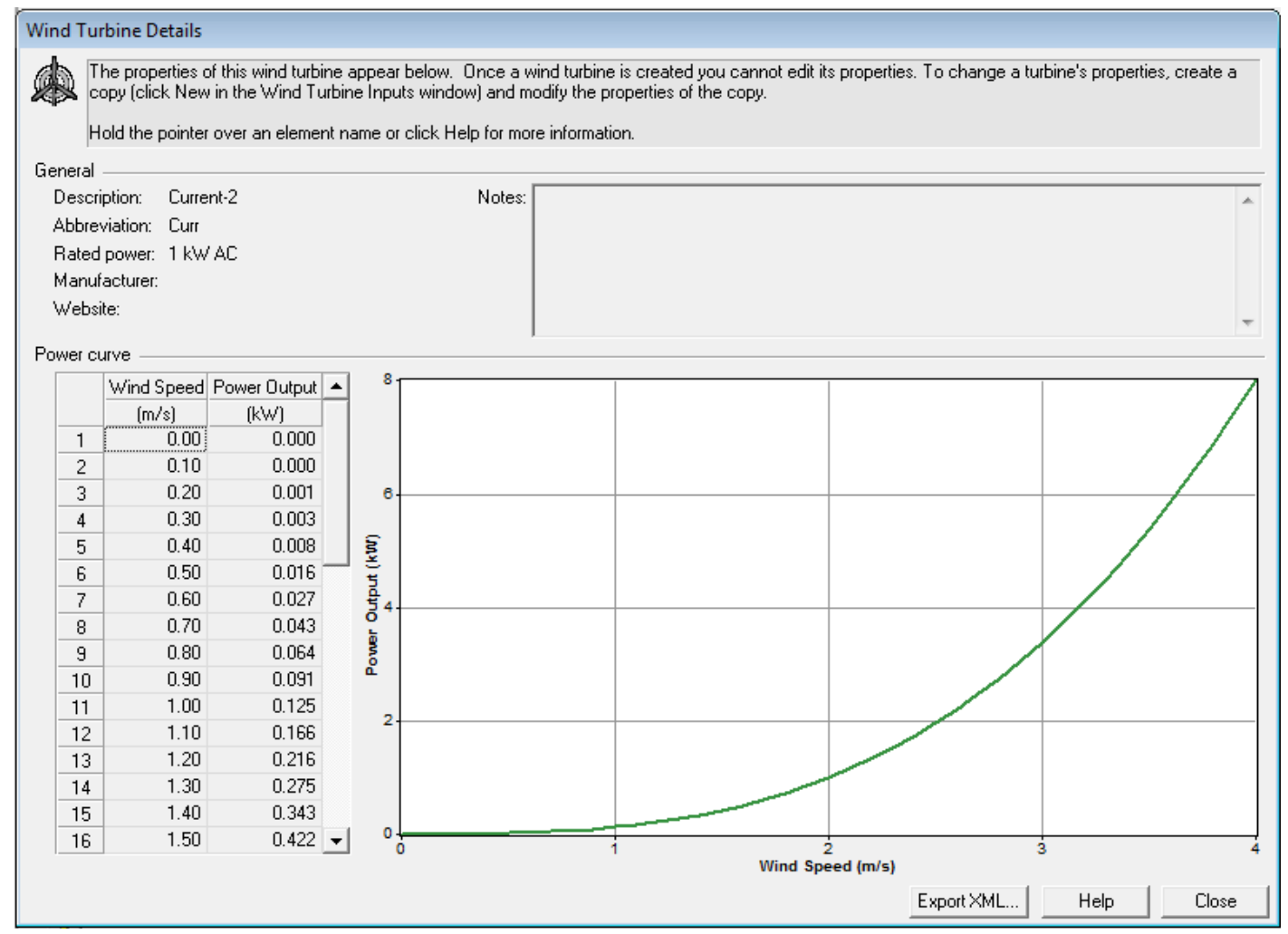

Figure 3. Parameters for the HOMER's model of a wind turbine. 


\section{Simulating Systems without Hydro Energy Contribution}

When the model of wind turbines is not available, the best choice will be the model of hydroelectric plant. The current energy resource presents values of capacity factor lower than those presented by hydro power and the equations are not similar. The power in a hydro power plant $P_{h y d}[\mathrm{~W}]$ is given by equation (4), where $\gamma\left[\mathrm{N} / \mathrm{m}^{3}\right]$ is the specific weight of water, $Q\left[\mathrm{~m}^{3} / \mathrm{s}\right]$ is the flow rate, $\mathrm{H}[\mathrm{m}]$ is the available head and $\eta_{\text {hyd }}[1]$ is the total performance of the hydro power plant.

$$
P_{\text {hyd }}=\gamma Q H \eta_{\text {hyd }}
$$

Equation (5) shows what will be done to use an internal model existing in Homer for run-of-river micro hydro power plants to simulate a current power plant. Substituting Equations (3) and (11) into (12) and defining that $\eta_{\text {hyd }}$ [1] is equal to $\eta_{\text {cur }}[1]$ and that $Q$ [ $\left.\mathrm{m}^{3} / \mathrm{s}\right]$ is equal to $V^{3}\left[\mathrm{~m}^{3} / \mathrm{s}^{3}\right]$, it is possible to write (13).

$$
\begin{gathered}
P_{\text {hyd }}=P_{\text {cur }} \\
H=\frac{\rho_{S W}}{2 \gamma} C_{P, \text { cur }} A_{\text {cur }}
\end{gathered}
$$

The flow rate and available head then take on new interpretations. Similar to the use of this model to simulate ocean wave power plants [10], the new interpretation of stream flow is associated with the variation of the energetic potential and available height is associated parameters related to energy conversion technology.

The HOMER simulates a "run-of-river" plant, with constant available head. [5] The Figure 4 shows the information that must be supplied to the power plant model used by Homer. Among the specifications of the turbine, the available head $[\mathrm{m}]$, the design flow rate $[\mathrm{L} / \mathrm{s}]$, minimum and maximum flow ratios as a percentage of the design flow rate and efficiency. There is a module for calculating the loss in the pipe, depending on the pipe length, diameter and roughness. For economic values, initial, replacement and operation and maintenance cost per year and life span. At the end, there is still the option to include a hydro power plant in all simulated systems or only in those systems for which it prove feasible.

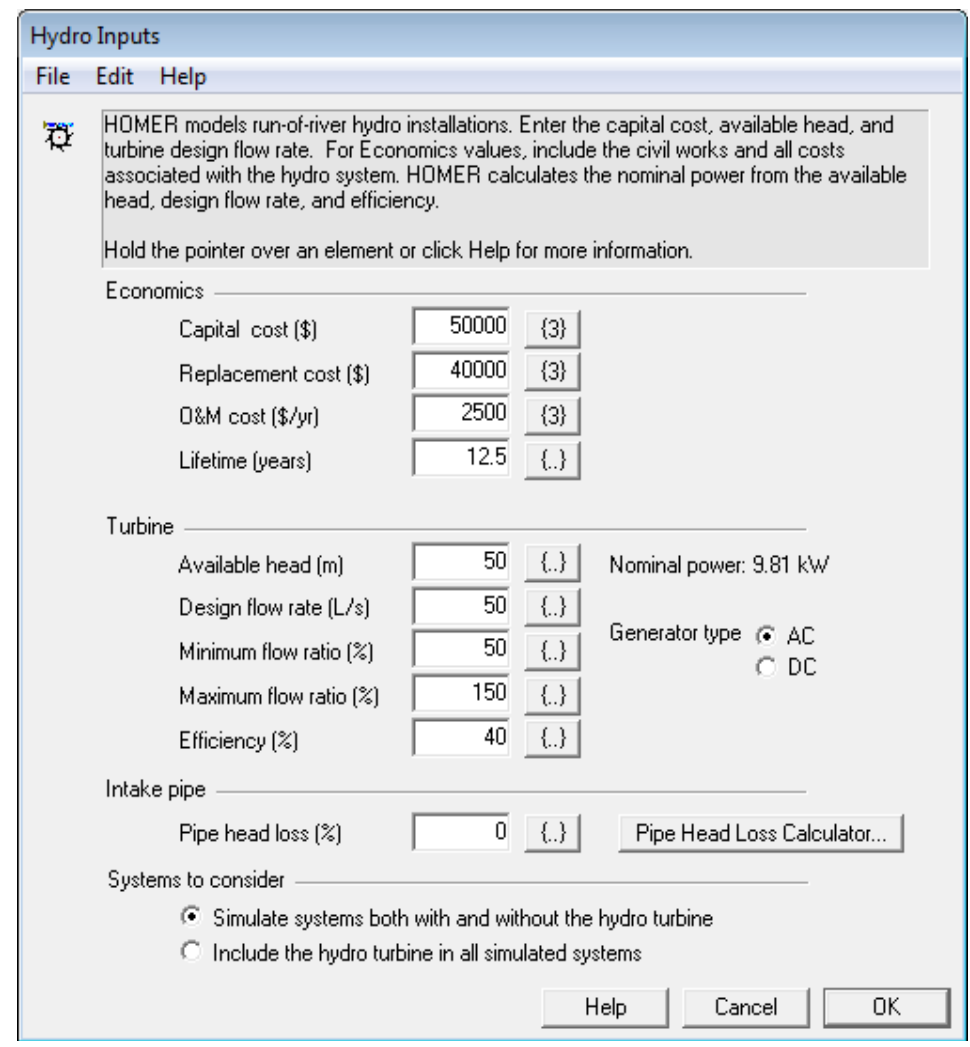

Figure 4. Parameters for the HOMER's model of a micro hydro power plant. 
The number of machines should be entered as multiples of the height and differences in costs must be entered as sensitivity variables, as shown in the next section. The application of this model therefore inserts important differences. Homer will not use these variables in the optimization of components, but they will be available in the sensitivity analysis. A post processing of the results will be necessary.

\section{Some Results and Discussion}

This study was performed to assess the integration of current power plants in hybrid systems situated not far from the coast. There are no commercially available technologies and this study was aimed to evaluate the use of the software for analyzing the feasibility of systems including current power plants. Homer could be applied to systems far from the coast, but in these conditions only larger systems would be viable, fleeing Homer goals.

The results can be used as a parameter for building a power plant or to purchase specific equipment, considering situations in which the software is applicable. The results can be used to compose a kind of feasibility window, characterizing the limits of cost and efficiency that would indicate the feasibility of implementation of a certain technology or a specific equipment in the studied system.

The application example is a wind diesel hybrid system located on a small farm in the municipality of Mos$\operatorname{tardas}^{1}$, in the state of Rio Grande do Sul, southern Brazil. This system has been the subject of a study, conducted by Ponticelli and Beluco [11] for inserting biodiesel and PV modules and will now also be considered as an application example for the use of Homer as a tool for analyzing the feasibility of hybrid systems including ocean or tidal current power plants. In this case, the location may only allow the use of ocean currents.

The farm lies between the Atlantic Ocean and the Patos Lake, in a region of rice cultivation and livestock activities, dedicating themselves to this second activity. The hybrid system is used to supply small mechanical drives and other minor loads. The system also supplies the electrical loads of the farmhouse when the interconnected system failure (which is not uncommon in the region!), but this was not simulated in a specific way. The system is shown in Figure 5 and the main result is shown in Figure 11.

Electrical loads have consumption value around $105 \mathrm{kWh}$ per day, kept constant by a control system which connects loads for heating water. There is also a water storage system, modeled on Homer as a deferrable load, with consumption of about 400 Wh per day.

The engine generator set is Branco [12], produced and distributed regionally, model BD $6500 \mathrm{CF}$ with $10 \mathrm{hp}$, with $5.5 \mathrm{kVA} / 5.0 \mathrm{~kW}$ nominal power. The wind turbine WES 5 [13] was employed, with $2.5 \mathrm{~kW}$ rated with three rotor blades $5 \mathrm{~m}$ diameter, with induction generator and IGBT converter. An anemometer connected to a control system allows controlling the speed of the turbine.

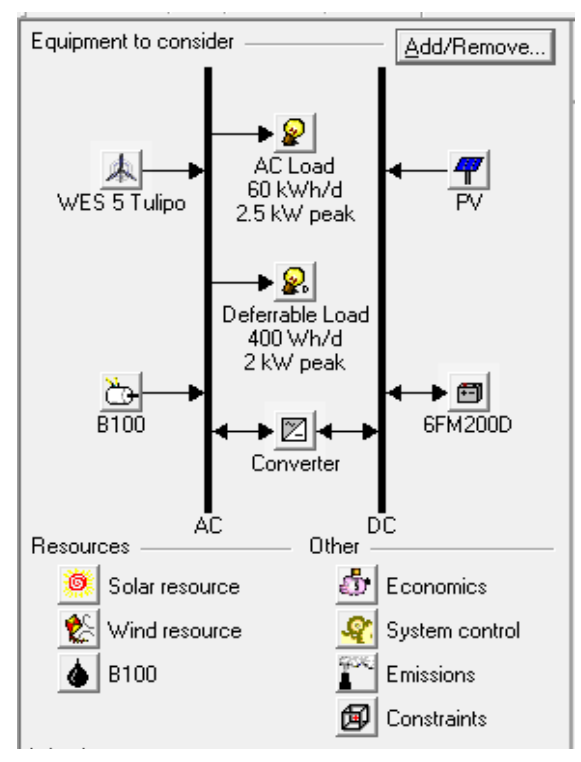

Figure 5. Hybrid system of the Reference [11].

${ }^{1}$ The city of Mostardas can be located on Google Maps [14] at http://goo.gl/maps/qlC8S. 
Figure 6 shows the wind speeds recorded in the first year of operation of the wind turbine, between August 2009 and July 2010.Data were obtained at 25 meters from the ground at approximately the same height as the wind turbine. Figure 7 shows the availability of solar power for the hybrid system, obtained through software Homer with the databases of NASA.
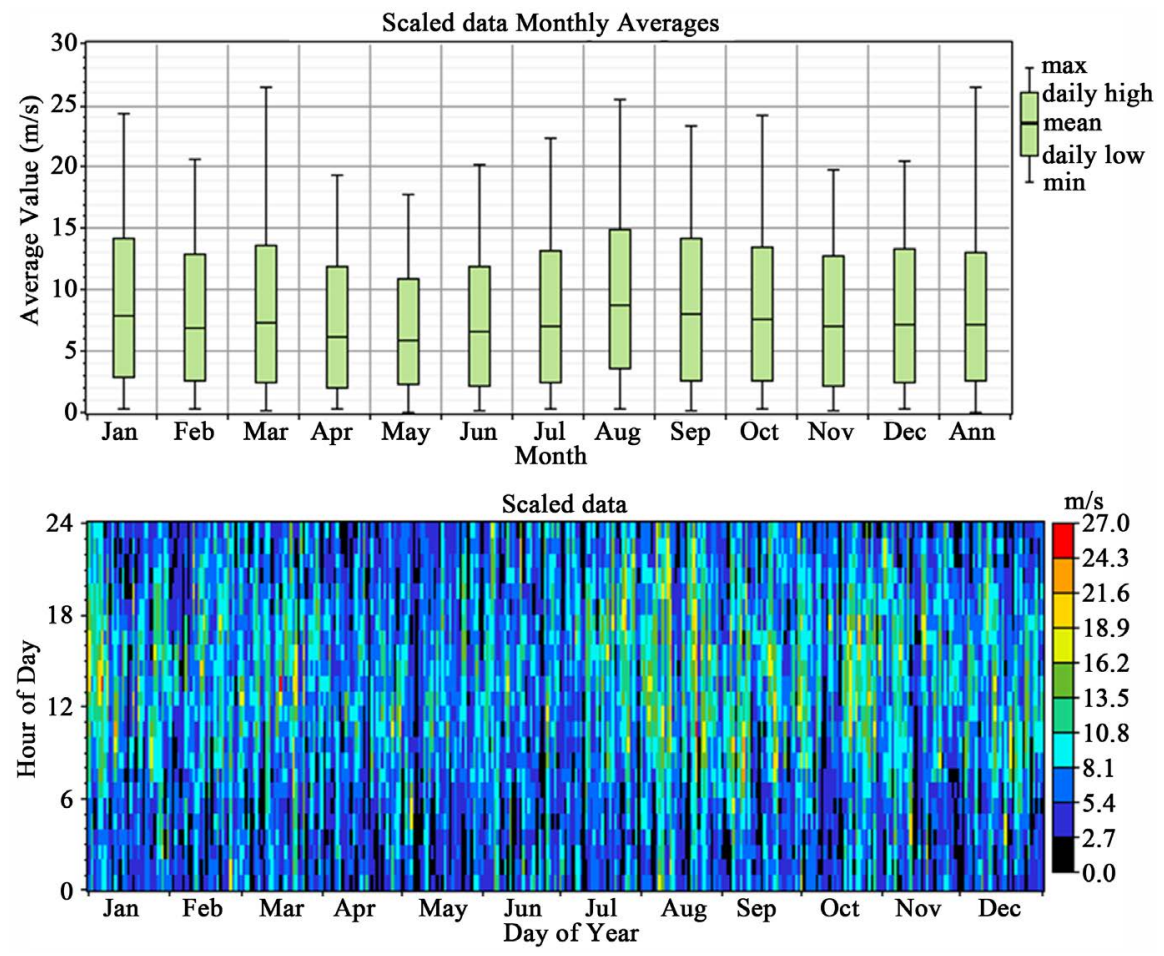

Figure 6. Wind speed data obtained in the first year of operation of the equipment.
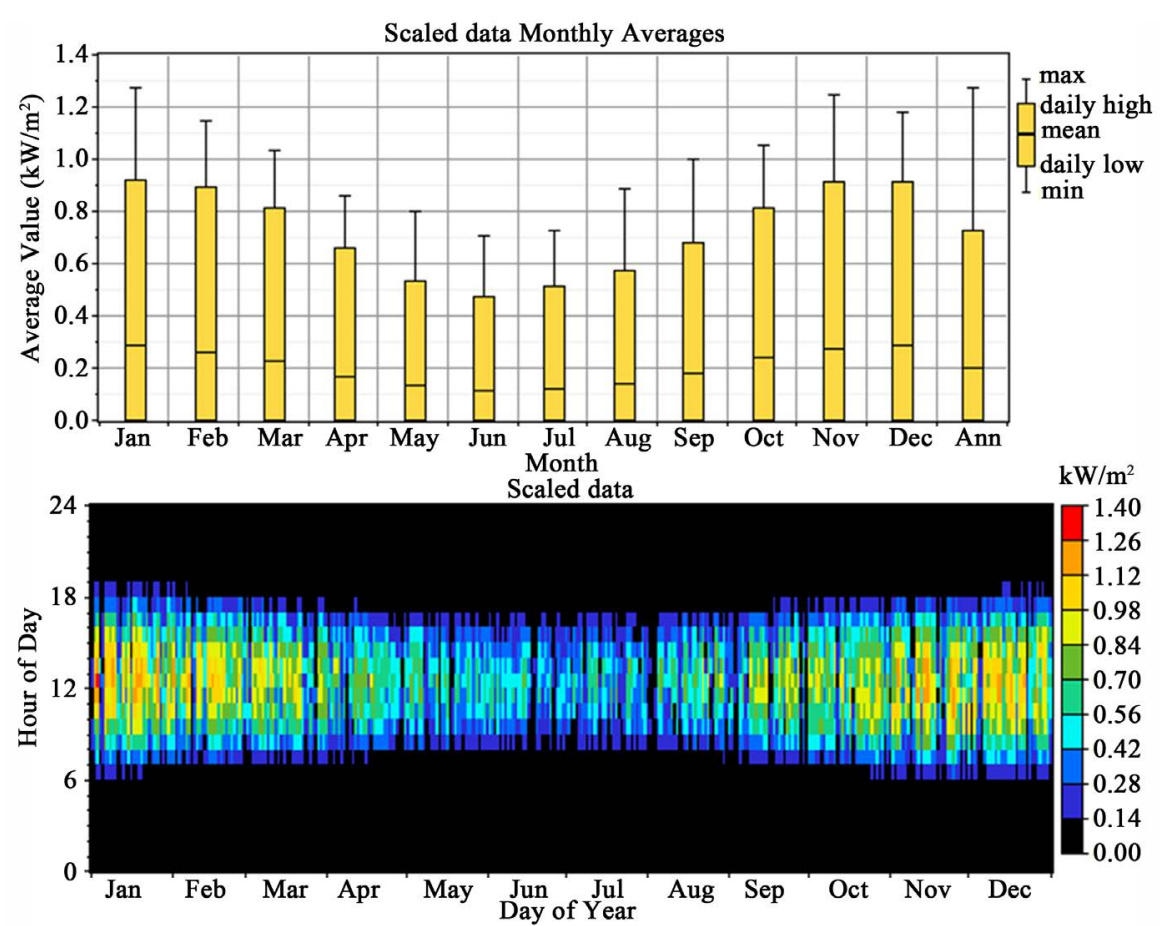

Figure 7. Availability of solar energy obtained by Homer with the databases of NASA. 
These two figures show two graphs each. The first graph shows maximum, medium and minimum values on the wind speed and solar radiation respectively over the months of the year. The second graph shows a representation of the distribution of wind velocity and solar radiation respectively over the days of the year, according to the color legends. The first graph in Figure 7 indicates the variability of wind and the second graph clearly shows the dark period in each day and the variation of daily insolation time throughout the year.

Figure 8(a) shows the system of Figure 5 with the inclusion of a current power plant. As this system already has wind turbines, the current power plant will be simulated with the model for hydroelectric power plants. The results obtained for this system are the goal of this case study.

Figure 8(b) shows the system of Figure 5 without wind turbines. This system will be simulated to be considered as a comparison reference between the two models for simulating current power plants. Figure 9(a) shows this system with the inclusion of a current power plant simulated with the model for wind turbines and Figure 9(b) shows this system with a current power plant simulated with the model for hydro power plants.

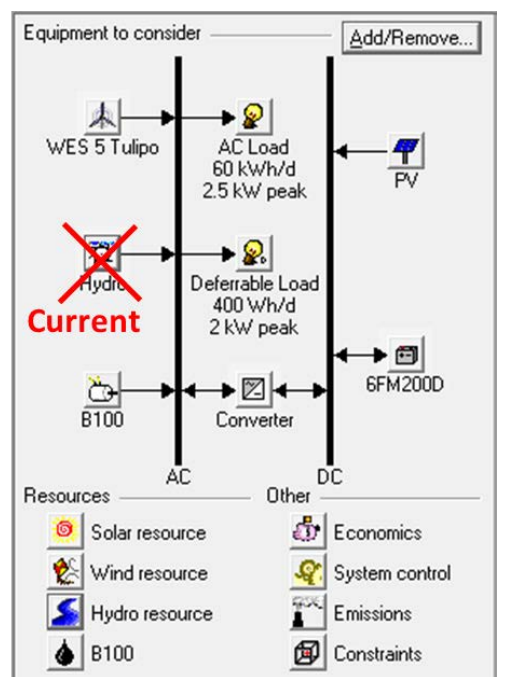

(a)

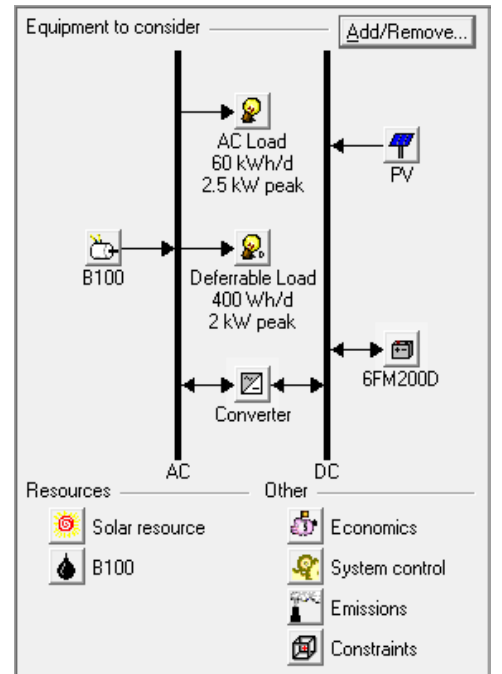

(b)

Figure 8. Hybrid system of the Reference [11], (a); and hybrid system including an ocean wave power plant on the (b).

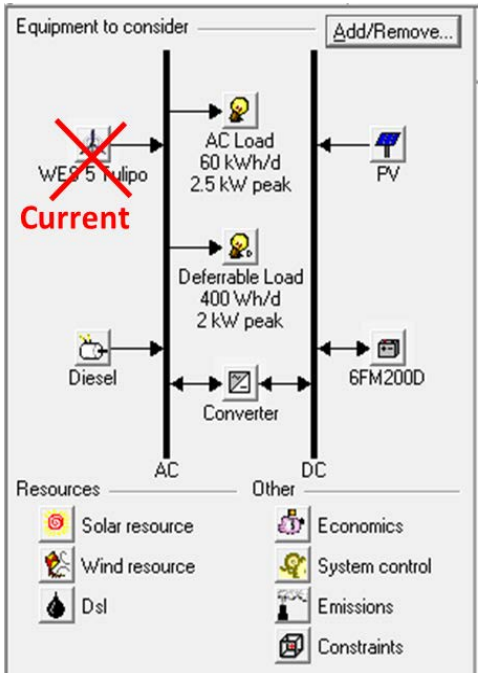

(a)

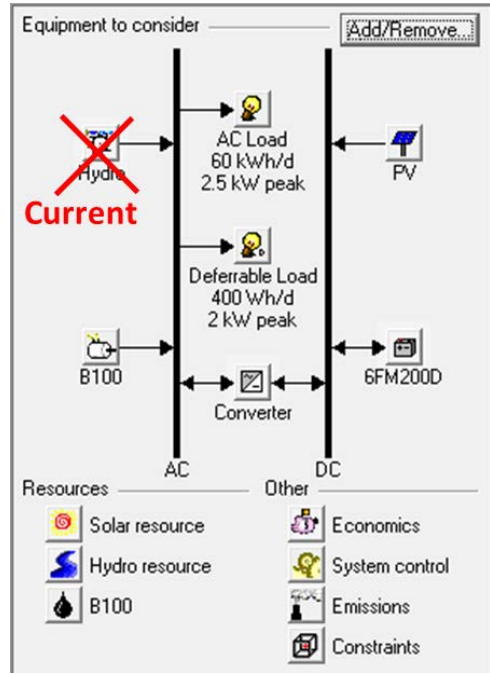

(b)

Figure 9. Hybrid system of the Reference [11], (a), and hybrid system including an ocean wave power plant on the (b). 
Figure 10 shows current speed data obtained in Tramandai ${ }^{2}$, in southern Brazil, during 1996. [15] This figure, like the previous ones, presents two graphs. The first chart shows maximum, medium and minimum values on the current speed over the months of the year. The second graph shows a representation of the distribution of current velocity over the days of the year, according to the color legend.

The following paragraphs describe the variables used in the simulations of the hybrid systems described above. This study is not exhaustive and only shows some details of the inclusion of current power plants in hybrid systems, simulated with the models described in the sections 4 and 5 this technical note.

The system of Figure 5 was simulated 2,100,000 times with 1750 optimization variables and 1200 sensitivity variables. The results of simulation of this system are the main result of Reference [11] and some resulas are shown in Figure 11.

The search space for this case was composed by $0.0 \mathrm{~kW}, 0.2 \mathrm{~kW}, 0.4 \mathrm{~kW}, 0.8 \mathrm{~kW}, 1.2 \mathrm{~kW}, 1.6 \mathrm{~kW}$ and 2.0 $\mathrm{kW}$ for PV array capacity; 0, 1, 2, 4 and 8 for the quantity of wind turbines; $0 \mathrm{~kW}$ and $5 \mathrm{~kW}$ for diesel generator capacity; 0, 2, 4 and 8 for the quantity of batteries; $0.00 \mathrm{~kW}, 0.25 \mathrm{~kW}, 0.50 \mathrm{~kW}, 1.00 \mathrm{~kW}$ and $2.00 \mathrm{~kW}$ for converter capacity. The sensitivity inputs was composed by $10 \mathrm{kWh} / \mathrm{d}, 20 \mathrm{kWh} / \mathrm{d}, 30 \mathrm{kWh} / \mathrm{d}, 40 \mathrm{kWh} / \mathrm{d}, 50 \mathrm{kWh} / \mathrm{d}$ and $60 \mathrm{kWh} / \mathrm{d}$ for AC load; $4.0 \mathrm{~m} / \mathrm{s}, 6.0 \mathrm{~m} / \mathrm{s}, 8.0 \mathrm{~m} / \mathrm{s}$ and $10.0 \mathrm{~m} / \mathrm{s}$ for wind speed; USD\$ 0.40/L, USD\$ 0.65/L, USD \$ 0.90/L, USD\$ 1.15/L and USD\$ 1.40/L for the price of biodiesel; 1.00, 0.50 and 0.10 for the PV capital cost, PV replacement cost and PV operation and maintenance costs multipliers, these last three related to each other. The PV costs multipliers were considered for other studies, not discussed here.

The system of Figure 8(a) is the system of Figure 5 with the inclusion of a current power plant described with the model for a hydro power plant. This system was simulated 552,960 times with 1536 optimization variables and 360 sensitivity variables. Some results of these simulations, being one of the main goal of this technical note, are shown in Figure 14 and Figure 15.

The search space for this case was composed of the following values: $0.0 \mathrm{~kW}, 0.2 \mathrm{~kW}, 0.4 \mathrm{~kW}, 0.8 \mathrm{~kW}, 1.2$ $\mathrm{kW}, 1.6 \mathrm{~kW}$ and $2.0 \mathrm{~kW}$ for PV array capacity; 0, 2, 4 and 8 for the quantity of wind turbines; $0 \mathrm{~kW}$ and $5 \mathrm{~kW}$ for diesel generator capacity; 0, 2, 4 and 8 for the quantity of batteries; $0.00 \mathrm{~kW}, 0.25 \mathrm{~kW}, 0.50 \mathrm{~kW}, 1.00 \mathrm{~kW}$ and $2.00 \mathrm{~kW}$ for converter capacity. The sensitivity inputs was composed of the following values: $10 \mathrm{kWh} / \mathrm{d}, 20$

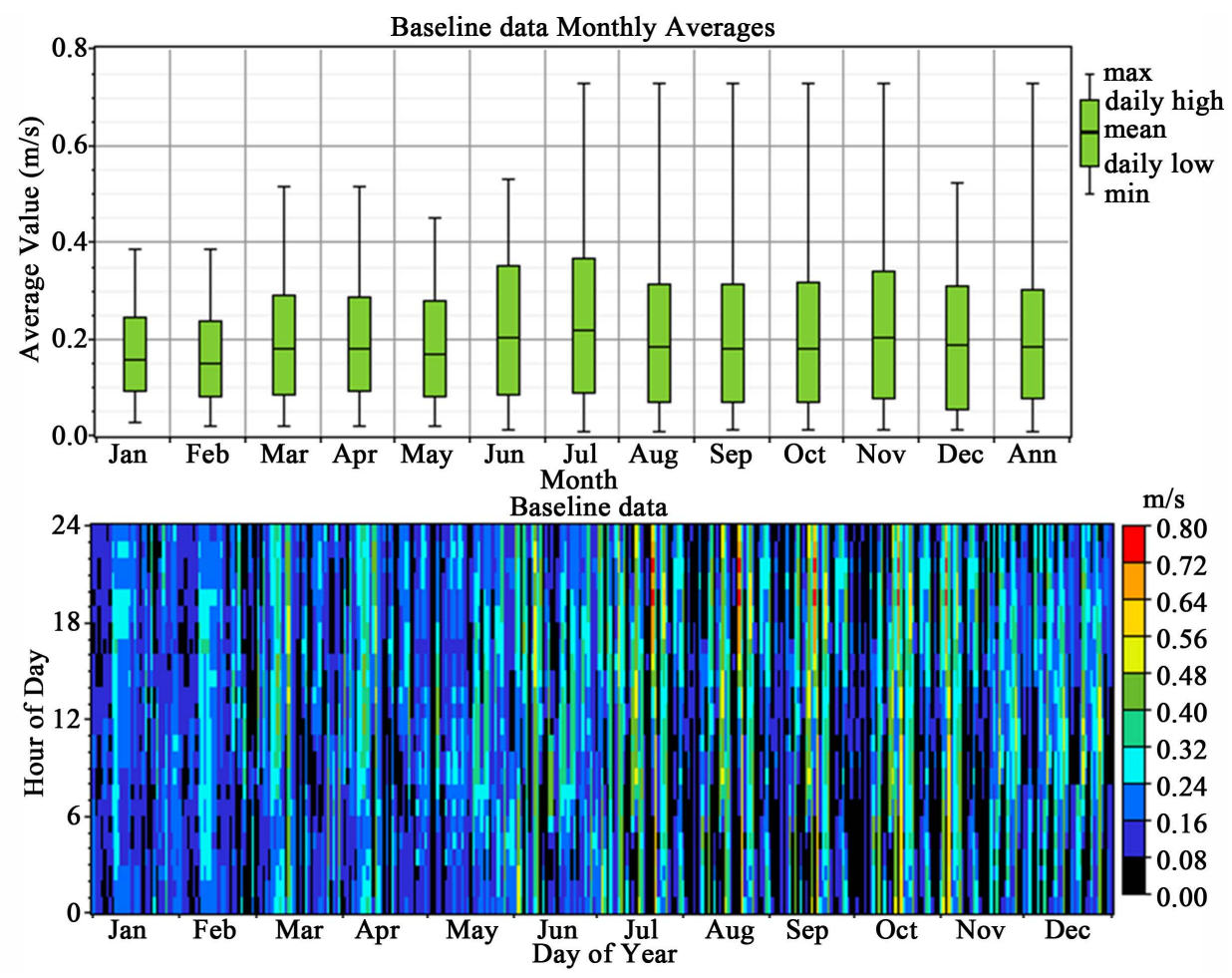

Figure 10. Current speed data obtained in Tramandaí, southern Brazil, in 1996.

\footnotetext{
${ }^{2}$ Tramandaí, in southern Brazil, can be located on Google Maps [14] at https://goo.gl/maps/BTQv4.
} 


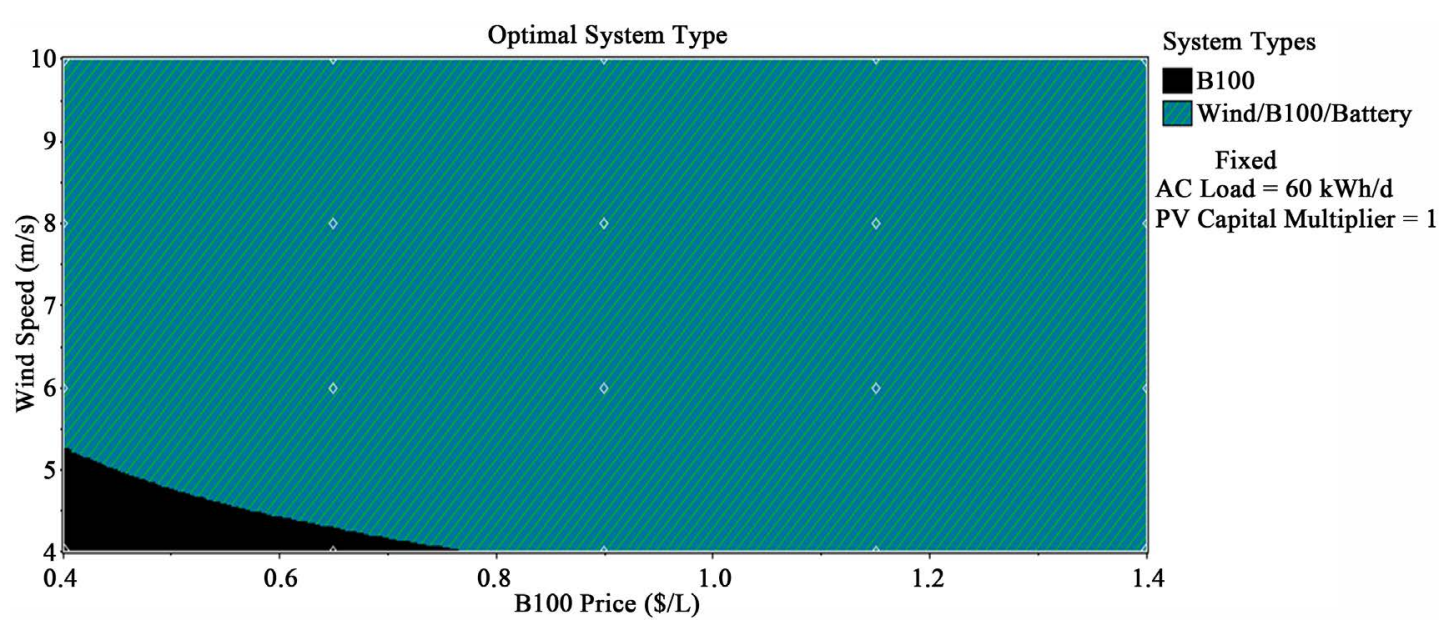

(a)

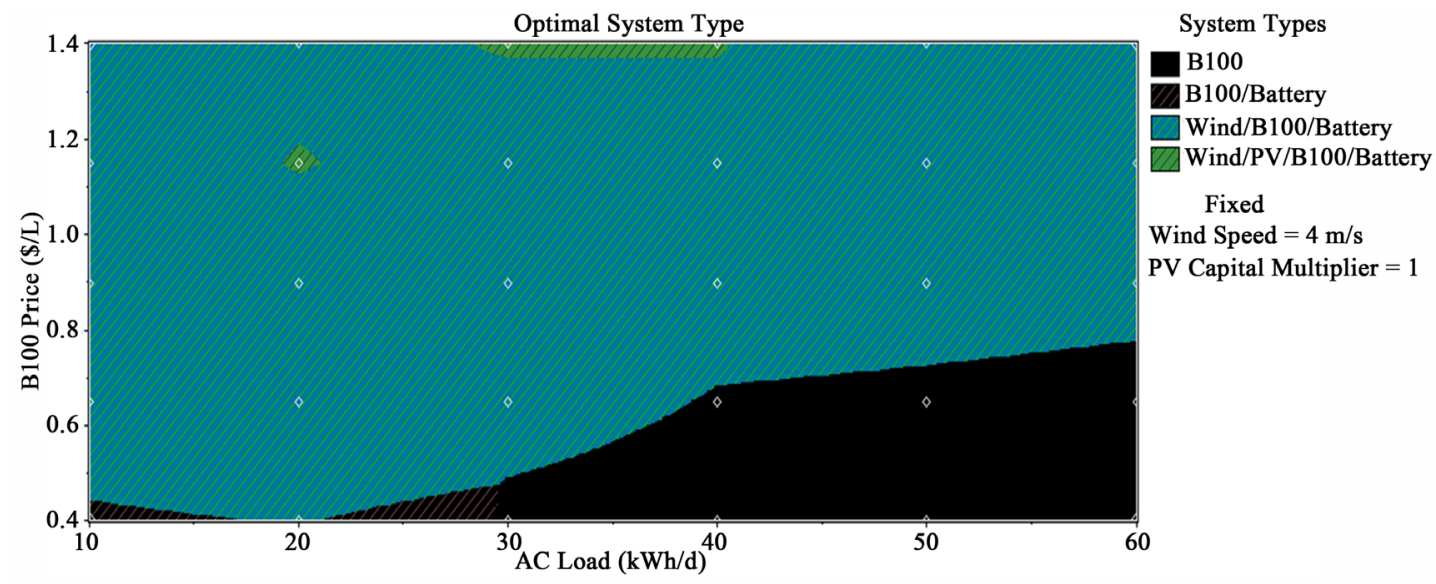

(b)

Figure 11. Optimization space for the system of Figure 5, showing (a) wind speed as a function of biodiesel price, for AC load of $60 \mathrm{kWh} / \mathrm{d}$, and (b) biodiesel price as a funciont of AC load, for wind speed of $4 \mathrm{~m} / \mathrm{s}$.

$\mathrm{kWh} / \mathrm{d}, 30 \mathrm{kWh} / \mathrm{d}, 40 \mathrm{kWh} / \mathrm{d}, 50 \mathrm{kWh} / \mathrm{d}$ and $60 \mathrm{kWh} / \mathrm{d}$ for AC load; $4 \mathrm{~m} / \mathrm{s}, 6 \mathrm{~m} / \mathrm{s}, 8 \mathrm{~m} / \mathrm{s}$ and $10 \mathrm{~m} / \mathrm{s}$ for wind speed; USD\$ 0.40/L, USD\$ 0.65/L, USD\$ 0.90/L, USD\$ 1.15/L and USD\$ 1.40/L for the price of biodiesel; one, two and four current energy conversion devices; USD\$ 8,000, USD\$ 16,000 and USD\$ 32,000 for the current power plant capital cost; USD\$ 4000, USD\$ 8000 and USD\$ 16,000 for the current power plant replacement cost; USD\$ 400 per year, USD\$ 800 per year and USD\$ 1600 per year for the current power plant operation and maintenance costs, these last four related to each other.

The systems in Figure 8(b), Figure 9(a) and Figure 9(b) are a reference for comparison. The system of Figure 8(b) was simulated 192,500 times with 350 optimization variables and 550 sensitivity variables. Some results of these simulations are shown in Figure 12.

The search space for this case was composed of the following values: $0.0 \mathrm{~kW}, 0.2 \mathrm{~kW}, 0.4 \mathrm{~kW}, 0.8 \mathrm{~kW}, 1.2$ $\mathrm{kW}, 1.6 \mathrm{~kW}$ and $2.0 \mathrm{~kW}$ for PV array capacity; $0 \mathrm{~kW}$ and $5 \mathrm{~kW}$ for diesel generator capacity; 0, 2, 4 and 8 for the quantity of batteries; $0.00 \mathrm{~kW}, 0.25 \mathrm{~kW}, 0.50 \mathrm{~kW}, 1.00 \mathrm{~kW}$ and $2.00 \mathrm{~kW}$ for converter capacity. The sensitivity inputs was composed of the following values: $10 \mathrm{kWh} / \mathrm{d}, 15 \mathrm{kWh} / \mathrm{d}, 20 \mathrm{kWh} / \mathrm{d}, 25 \mathrm{kWh} / \mathrm{d}, 30 \mathrm{kWh} / \mathrm{d}, 35$ $\mathrm{kWh} / \mathrm{d}, 40 \mathrm{kWh} / \mathrm{d}, 45 \mathrm{kWh} / \mathrm{d}, 50 \mathrm{kWh} / \mathrm{d}, 55 \mathrm{kWh} / \mathrm{d}$ and $60 \mathrm{kWh} / \mathrm{d}$ for AC load; USD\$ 0.40/L, USD\$ 0.65/L, USD \$ 0.90/L, USD\$ 1.15/L and USD\$ 1.40/L for the price of biodiesel; 1.00, 0.50 and 0.10 for the PV capital cost, PV replacement cost and PV operation and maintenance costs multipliers, these last three related to each other.

This system is equal to that of Figure 5, excluding wind turbines so that their results are compared with the inclusion of current power plants described according to the two models discussed. The PV costs multipliers 


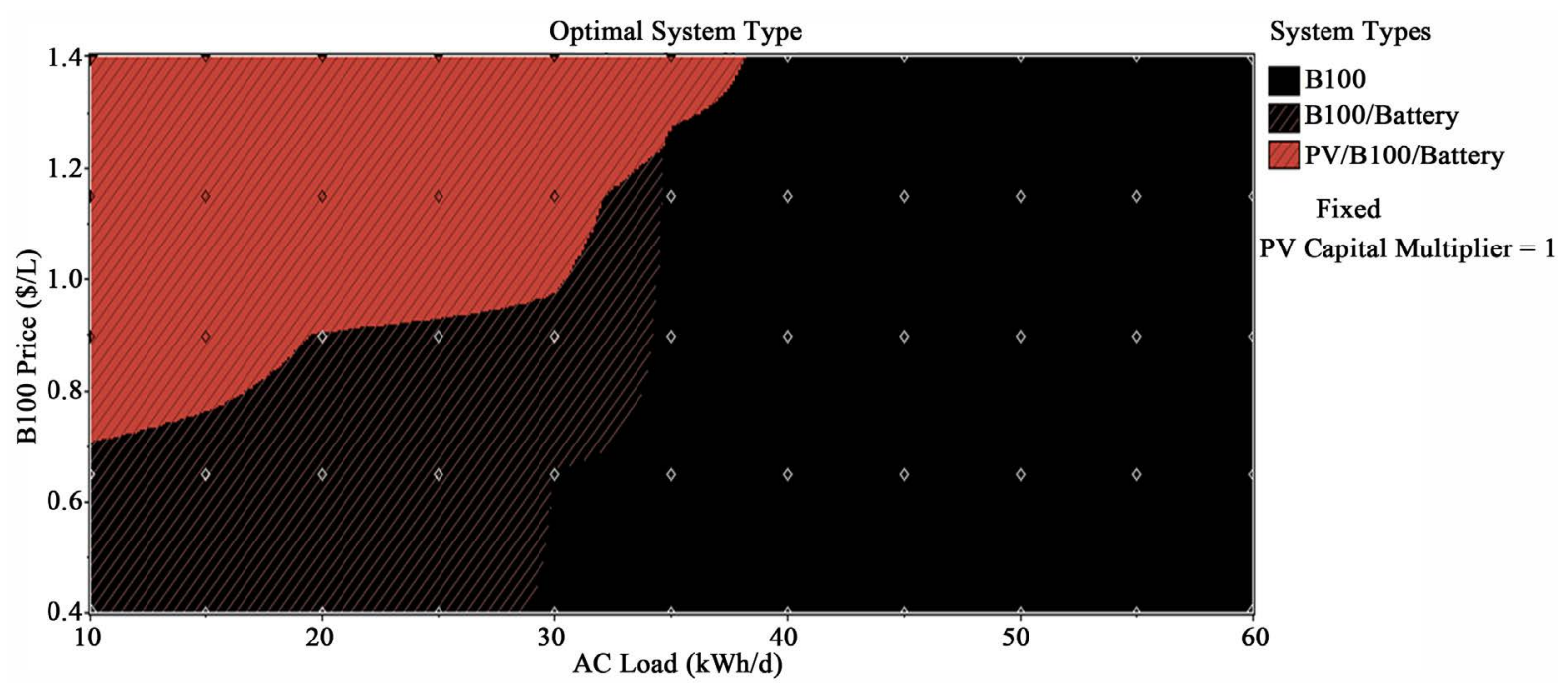

Figure 12. Optimization space for the system of Figure 8(b), showing biodiesel price as a funciont of AC load.

were considered for other studies.

The system of Figure 9(a) was simulated 1,155,000 times with 1400 optimization variables and 850 sensitivity variables. The search space was composed of the following values: $0.0 \mathrm{~kW}, 0.2 \mathrm{~kW}, 0.4 \mathrm{~kW}, 0.8 \mathrm{~kW}, 1.2 \mathrm{~kW}$, $1.6 \mathrm{~kW}$ and $2.0 \mathrm{~kW}$ for PV array capacity; 0, 1, 2 and 4 for the quantity of current turbines; $0 \mathrm{~kW}$ and $5 \mathrm{~kW}$ for diesel generator capacity; 0, 2, 4 and 8 for the quantity of batteries; $0.00 \mathrm{~kW}, 0.25 \mathrm{~kW}, 0.50 \mathrm{~kW}, 1.00 \mathrm{~kW}$ and $2.00 \mathrm{~kW}$ for converter capacity. The sensitivity inputs was composed of the following values: $10 \mathrm{kWh} / \mathrm{d}, 15$ $\mathrm{kWh} / \mathrm{d}, 20 \mathrm{kWh} / \mathrm{d}, 25 \mathrm{kWh} / \mathrm{d}, 30 \mathrm{kWh} / \mathrm{d}, 35 \mathrm{kWh} / \mathrm{d}, 40 \mathrm{kWh} / \mathrm{d}, 45 \mathrm{kWh} / \mathrm{d}, 50 \mathrm{kWh} / \mathrm{d}, 55 \mathrm{kWh} / \mathrm{d}$ and $60 \mathrm{kWh} / \mathrm{d}$ for AC load; $0.182 \mathrm{~m} / \mathrm{s}, 0.750 \mathrm{~m} / \mathrm{s}, 1.000 \mathrm{~m} / \mathrm{s}$ and $1.250 \mathrm{~m} / \mathrm{s}$ for current speed; USD\$ 0.40/L, USD \$ 0.65/L, USD\$ 0.90/L, USD\$ 1.15/L and USD\$ 1.40/L for the price of biodiesel; 1.00, 0.50 and 0.25 for the current power plant capital cost, current power plant replacement cost and current power plant operation and maintenance costs multipliers.

Some results of these simulations are shown in Figure 13. In this case the current power plants are included as wind turbines, with number of energy conversion devices remaining as optimization variables and capital costs, replacement costs and operation and maintenance costs multipliers, as well as the scaled values of current speed, remaining as sensitivity variables.

The system of Figure 9(b) was simulated 1,347,500 times with 700 optimization variables and 1925 sensitivity variables. The search space was composed of the following values: $0.0 \mathrm{~kW}, 0.2 \mathrm{~kW}, 0.4 \mathrm{~kW}, 0.8 \mathrm{~kW}, 1.2 \mathrm{~kW}$, $1.6 \mathrm{~kW}$ and $2.0 \mathrm{~kW}$ for PV array capacity; 0, 1, 2 and 4 for the quantity of current turbines; $0 \mathrm{~kW}$ and $5 \mathrm{~kW}$ for diesel generator capacity; $0,1,2,4$ and 8 for the quantity of batteries; $0.00 \mathrm{~kW}, 0.25 \mathrm{~kW}, 0.50 \mathrm{~kW}, 1.00 \mathrm{~kW}$ and $2.00 \mathrm{~kW}$ for converter capacity.

The sensitivity inputs for this case was composed of the following values: $10 \mathrm{kWh} / \mathrm{d}, 15 \mathrm{kWh} / \mathrm{d}, 20 \mathrm{kWh} / \mathrm{d}$, $25 \mathrm{kWh} / \mathrm{d}, 30 \mathrm{kWh} / \mathrm{d}, 35 \mathrm{kWh} / \mathrm{d}, 40 \mathrm{kWh} / \mathrm{d}, 45 \mathrm{kWh} / \mathrm{d}, 50 \mathrm{kWh} / \mathrm{d}, 55 \mathrm{kWh} / \mathrm{d}$ and $60 \mathrm{kWh} / \mathrm{d}$ for AC load; $0 \mathrm{~L} / \mathrm{s}$, $30 \mathrm{~L} / \mathrm{s}, 60 \mathrm{~L} / \mathrm{s}, 90 \mathrm{~L} / \mathrm{s}$ and $120 \mathrm{~L} / \mathrm{s}$ for stream flow; USD\$ 0.40/L, USD\$ 0.65/L, USD\$ 0.90/L, USD\$ 1.15/L and USD\$ 1.40/L for the price of biodiesel; 1.00, 0.50 and 0.10 for the PV capital cost, PV replacement cost and PV operation and maintenance costs multipliers, these last three related to each other. In this case, the current power plants are included as hydro power plants, with all related variables as sensitivity variables. The difficulties associated with this characteristic of the model are discussed further below.

The optimization space shown in Figure 11(a) is one of the results presented by Ponticelli and Beluco [11]. It is a typical result for wind speed as a function of diesel or biodiesel price, as shown also for example by Reference [11], for wind diesel hybrid systems. For comparison with the results as presented in this work, Figure 11(b) shows the optimization space given in price of biodiesel as a function of AC load.

The results in Figure 11(b) corresponds to wind speed of $4 \mathrm{~m} / \mathrm{s}$. There are solutions composed only by biodiesel generator and solutions including batteries, there are solutions including also wind turbines and, occupying a smaller area in optimization space, there are solutions also including PV modules. Above just over $5 \mathrm{~m} / \mathrm{s}$, all solutions include wind turbine, biodiesel generator set and batteries. 


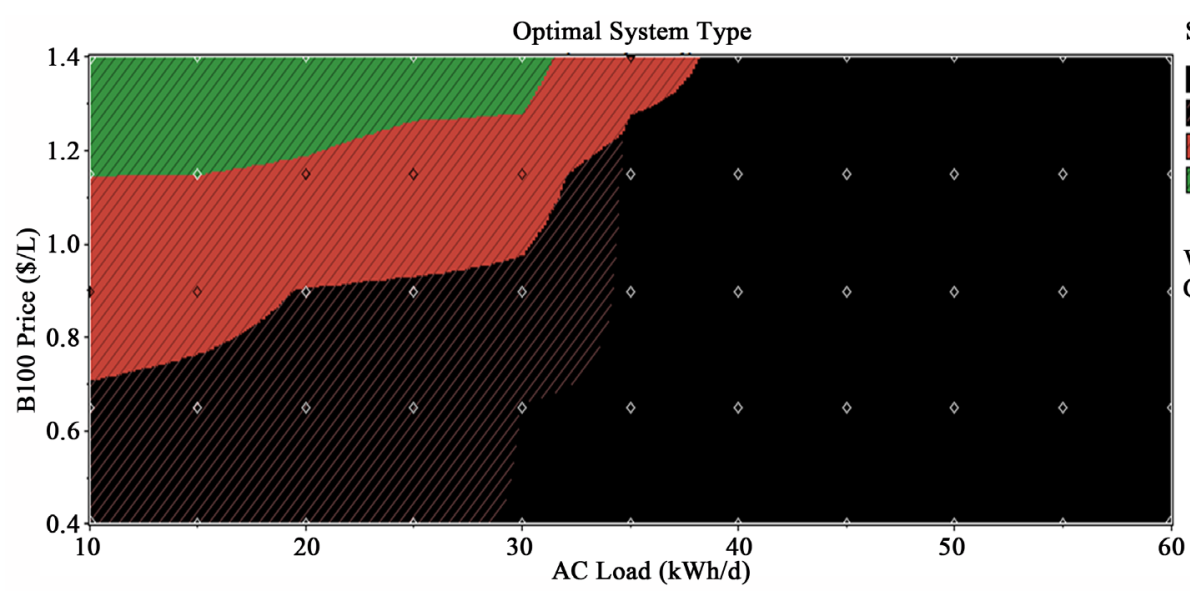

System Types

B100

7/B100/Battery

DPV/B100/Battery

$\triangle$ Wind/PV/B100/Battery

Fixed

Wind Speed $=0.75 \mathrm{~m} / \mathrm{s}$

Curr Capital Multiplier $=1$

(a)

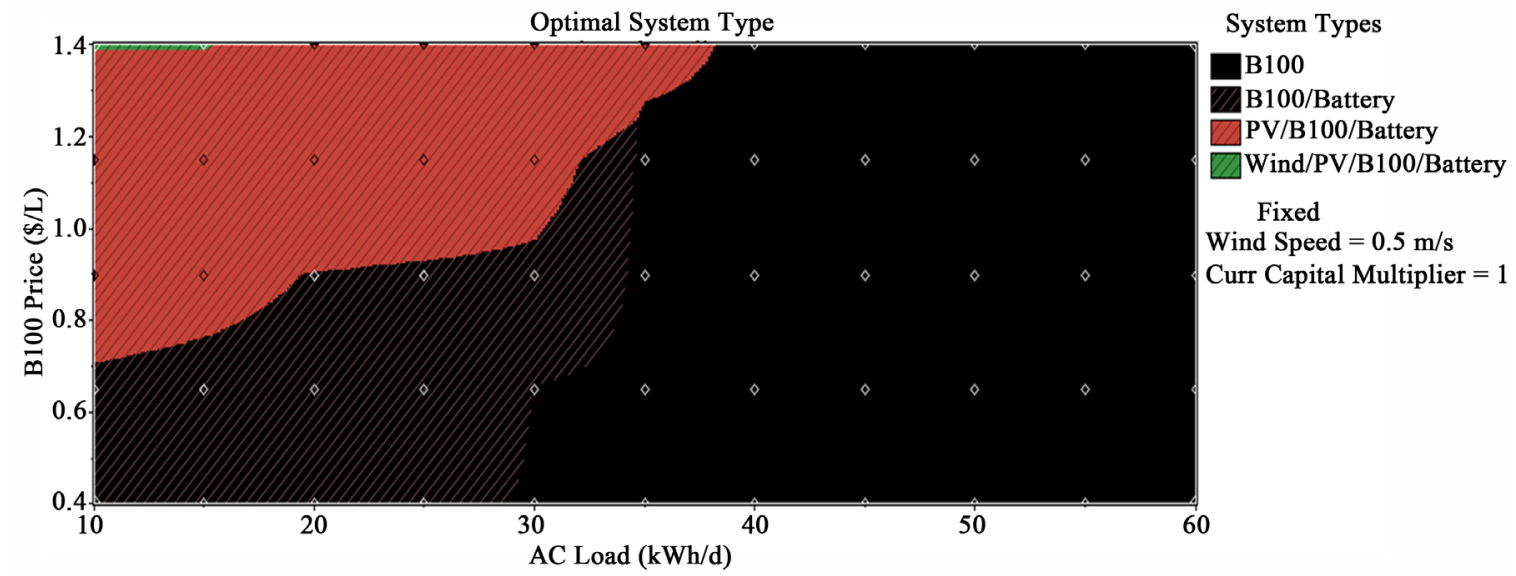

(b)

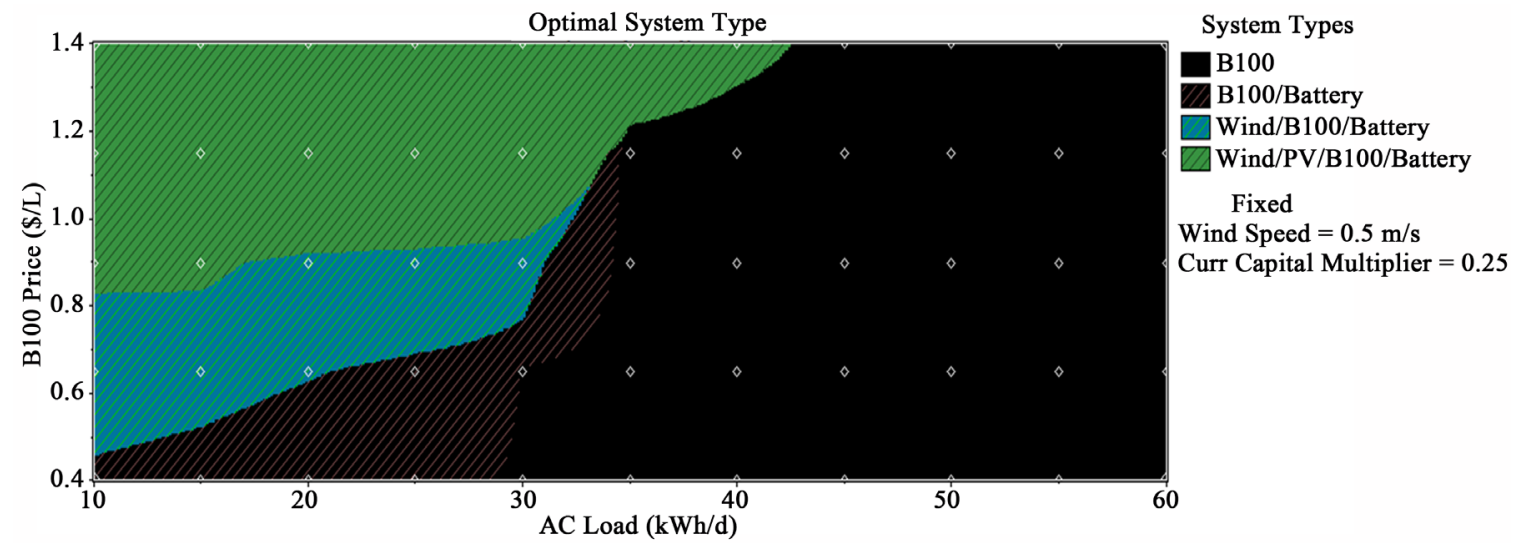

(c)

Figure 13. Optimization space for the system of Figure 9(a), showing biodiesel price as a funciont of AC load for (a) current speed of $0.75 \mathrm{~m} / \mathrm{s}$ and current capital cost multiplier equal to 1.00; (b) current speed of $0.50 \mathrm{~m} / \mathrm{s}$ and current capital cost multiplier equal to 0.50 ; (c) current speed of $0.50 \mathrm{~m} / \mathrm{s}$ and current capital cost multiplier equal to 0.25 .

The case study presented by Ponticelli and Beluco [11] suggests a viable solution by combining two $2.5 \mathrm{~kW}$ wind turbine with a $5 \mathrm{~kW}$ biodiesel gen set and four 200 Ah battery to supply an AC load of $60 \mathrm{kWh} / \mathrm{dand}$ a deferrable load of $400 \mathrm{Wh} / \mathrm{d}$. The initial cost is USD 24,000 and the cost of energy is USD\$ 0.375/kWh (if biodiesel price is USD\$ 0.90 per liter), with a renewable fraction equal to 0.79 . 
The goal is to know the effect of the inclusion of current power plants in this system. Before that, this system will be simulated without wind turbines and further, for comparison, this system will be simulated with current power plants described by the two models discussed above. So this initial system will be simulated again, this time to assess the inclusion of current power plants (described with the Homer's model for hydro).

Figure 12 shows the optimization space for the system of Figure 8(b). This system was simulated without the contribution of wind turbines to allow a comparison between the models for description of current power plants. The optimization space includes solutions with biodiesel gen set only, solutions with biodiesel gen set supported by batteries and solutions including also PV modules.

Approximately half the optimization space, corresponding to larger loads, presents solutions composed solely by biodiesel generator. Combinations of biodiesel generator and batteries have the capacity to supply the smaller loads, with the rise in the price of biodiesel clearing the way for viable solutions including PV modules. In general, the cost of energy of this optimization space is greater than the cost of energy of the optimization space shown in Figure 8(b) as a function of the components of the solutions in each space.

Figure 13 shows optimization spaces for the system of Figure 9(a), corresponding to the system of Figure 8(b) with the inclusion of a current power plant simulated with the Homer's model for wind turbines, as described in the Section 4 of this paper. In (a) and (b), the separation line between the black region (plain black and dashed black) and other regions is identical to the separation line that appears in Figure 12.

Figure 13(a) shows biodiesel price as a function of AC load for current speed of $0.75 \mathrm{~m} / \mathrm{s}$ and current capital cost multiplier equal to 1.00. Dashed red region, before dedicated to solutions including PV modules, is now invaded by the dashed green solutions, which also include equipment for converting the energy of currents. For the higher cost of conversion equipment, the current speed of $0.75 \mathrm{~m} / \mathrm{s}$ is sufficient to provide viable solutions.

Figure 13(b) shows biodiesel price as a function of AC load for current speed of $0.50 \mathrm{~m} / \mathrm{s}$ and current capital cost multiplier equal to 0.50 . Here, a lower current speed reduces solutions including current power plants, which appear in a restricted area in the upper left corner. It is noteworthy that this value of the current power plant capital cost multiplier and the relatively low value of the current speed would leave the current power plants with competitive prices compared to other renewable resources.

Figure 13(c) shows biodiesel price as a function of AC load for current speed of $0.50 \mathrm{~m} / \mathrm{s}$ and current capital cost multiplier equal to 0.25 . This optimization space shows a reduction of the area in black (plain black and dashed black). This optimization space also presents an increase of the area corresponding to solutions including current power plants (blue dashed and green dashed). This value of the current power plant capital cost multiplier would make the current power plants competitive even with hydro power.

Optimization spaces corresponding to higher values of current speed and lower values for the current power plant capital cost multiplier result in increasing percentage of solutions including current power plants. In these optimization spaces and earlier, the lines of separation between the regions corresponding to the different solutions actually establish regions where price differences between the optimal solutions and the first (and even the second or third) "non-optimal” solutions are very small.

Optimization spaces obtained with the simulation of the system of Figure 9(b) is approximately identical to the optimization spaces of Figure 13. The main difference between the two models that can be employed is that for one of them the number of conversion devices is an optimization variable while for the other this number is a sensitivity variable. This difference requires optimization spaces corresponding to different values of the number of devices to be compared so that the final result can be obtained. The drawing up of three-dimensional graphics, specifically in this case, showing optimization spaces as surfaces, can improve and facilitate the analysis of the simulation results provided by Homer and the comparison of various optimization spaces.

Figure 14 and Figure 15 show optimization spaces for the system of Figure 8(a), corresponding to the system of Figure 5 with the inclusion of a current power plant simulated with the Homer's model for hydro power plants, as described in the Section 5 of this technical note. Figure 14 show wind speed as a function of biodiesel price for AC load of $60 \mathrm{kWh} / \mathrm{d}$ and one, two and four current energy conversion devices respectively in (a), (b) and (c), with values of total net present cost superimposed on graphic. Figure 15 show biodiesel price as a function of AC load for wind speed of $8 \mathrm{~m} / \mathrm{s}$ and one, two and four current energy conversion devices respectively in (a), (b) and (c), with values of total net present cost superimposed on graphic.

The simulations performed for the current velocities measured on the continental shelf of southern Brazil indicated that no viable solutions would include these energy conversion devices. The optimization spaces shown in Figure 14 and Figure 15 were obtained for the current flow shown in Figure 10 scaled to an annual average 


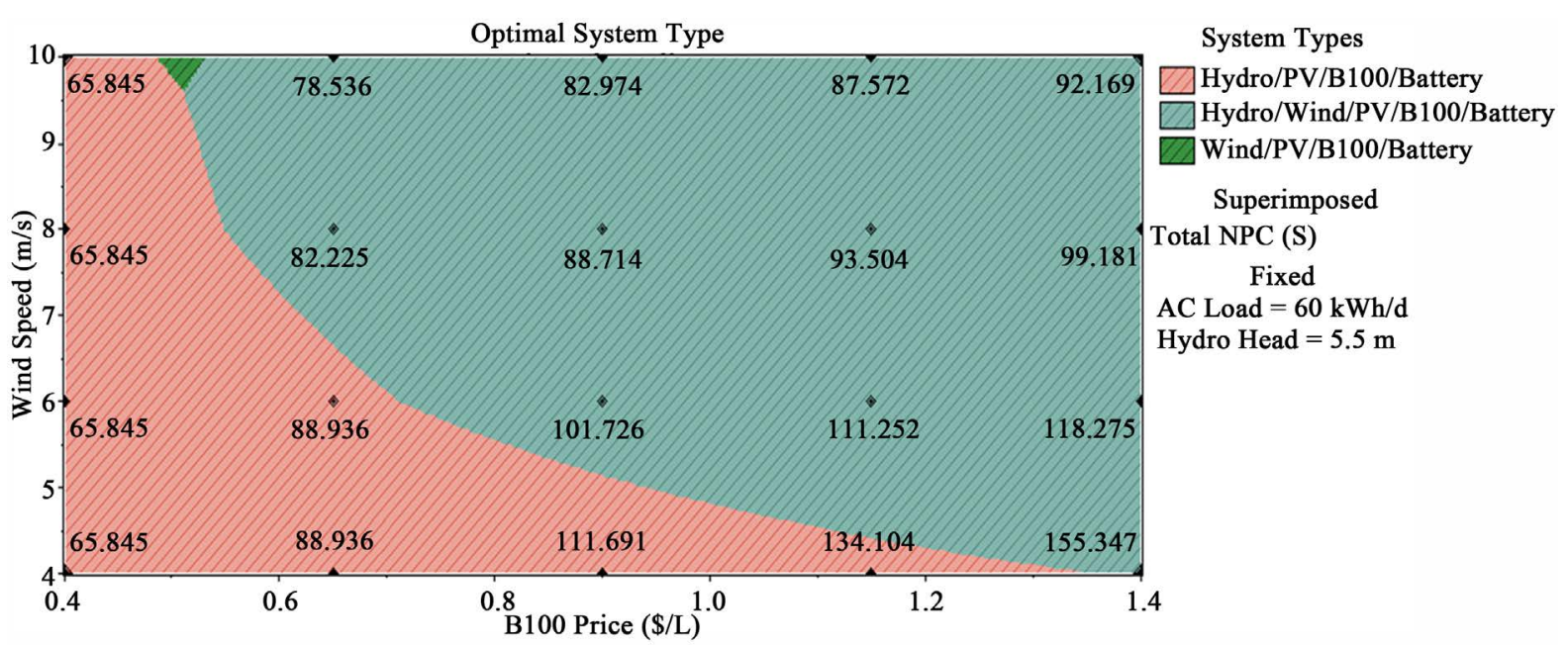

(a)

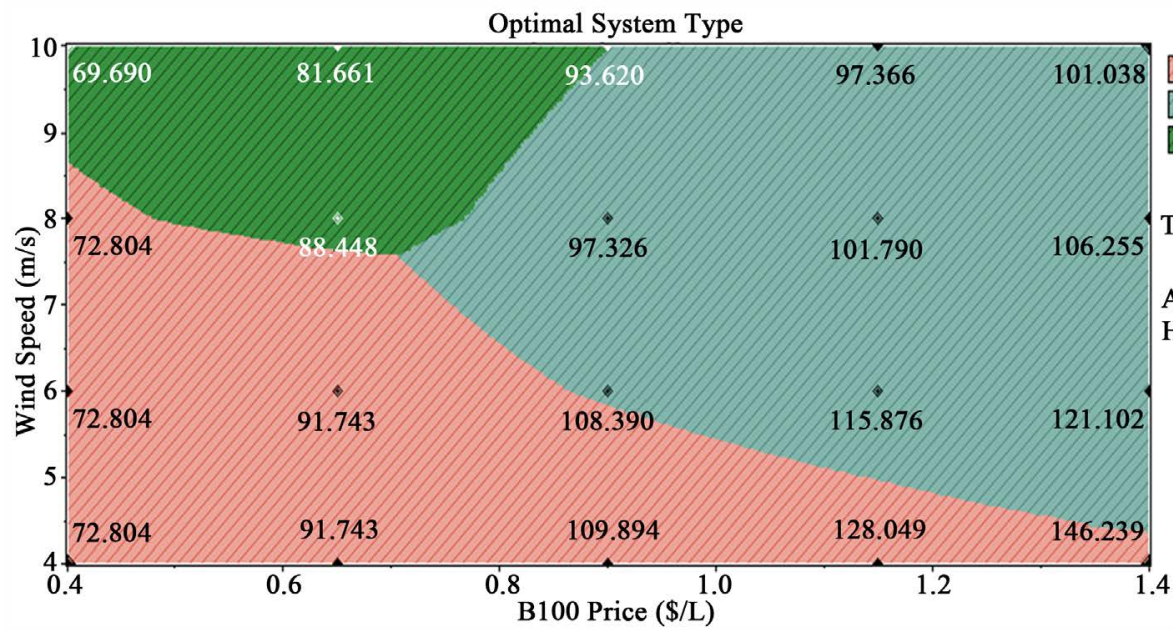

System Types

$\square$ Hydro/PV/B100/Battery

$\square$ Hydro/Wind/PV/B100/Battery

$\nabla$ Wind/PV/B100/Battery

Superimposed

Total NPC (S)

AC Load $=60 \mathrm{kWh} / \mathrm{d}$

Hydro Head $=11 \mathrm{~m}$

(b)

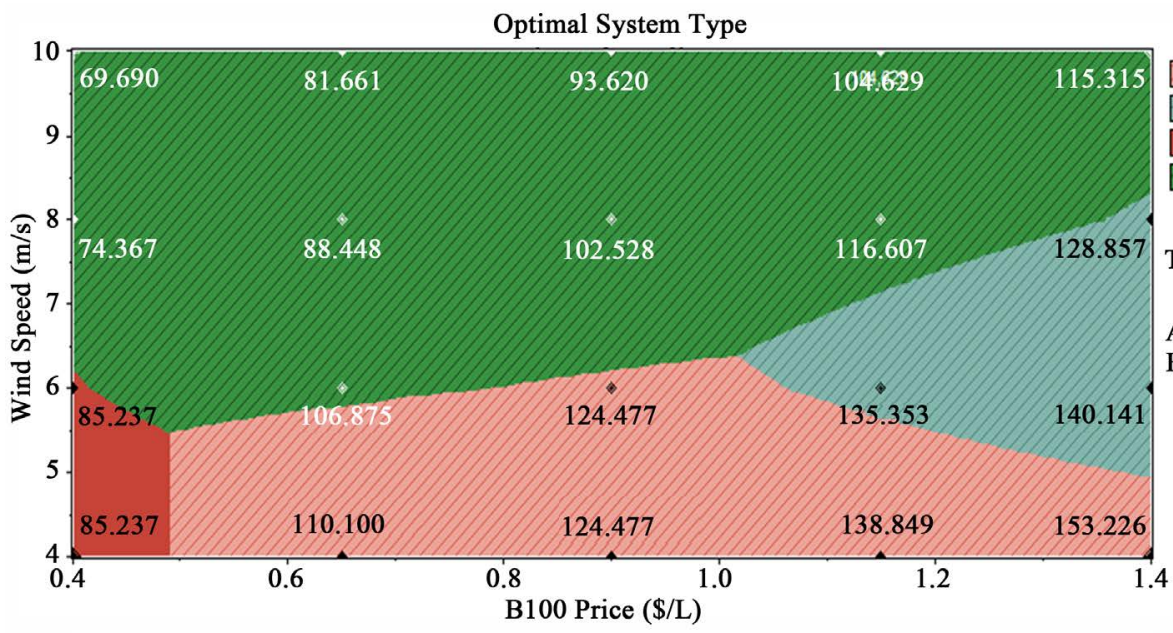

System Types

Hydro/PV/B100/Battery

$\square$ Hydro/Wind/PV/B100/Battery

PV/B100

Wind/PV/B100/Battery

Superimposed

Total NPC (S)

Fixed

AC Load $=60 \mathrm{kWh} / \mathrm{d}$

Hydro Head $=22 \mathrm{~m}$

(c)

Figure 14. Optimization space for the system of Figure 8(a), showing wind speed as a function of biodiesel price for AC load of $60 \mathrm{kWh} / \mathrm{d}$ and (a) one current energy conversion device; (b) two current energy conversion devices; (c) four current energy conversion devices, with values of total net present cost superimposed on graphic. 


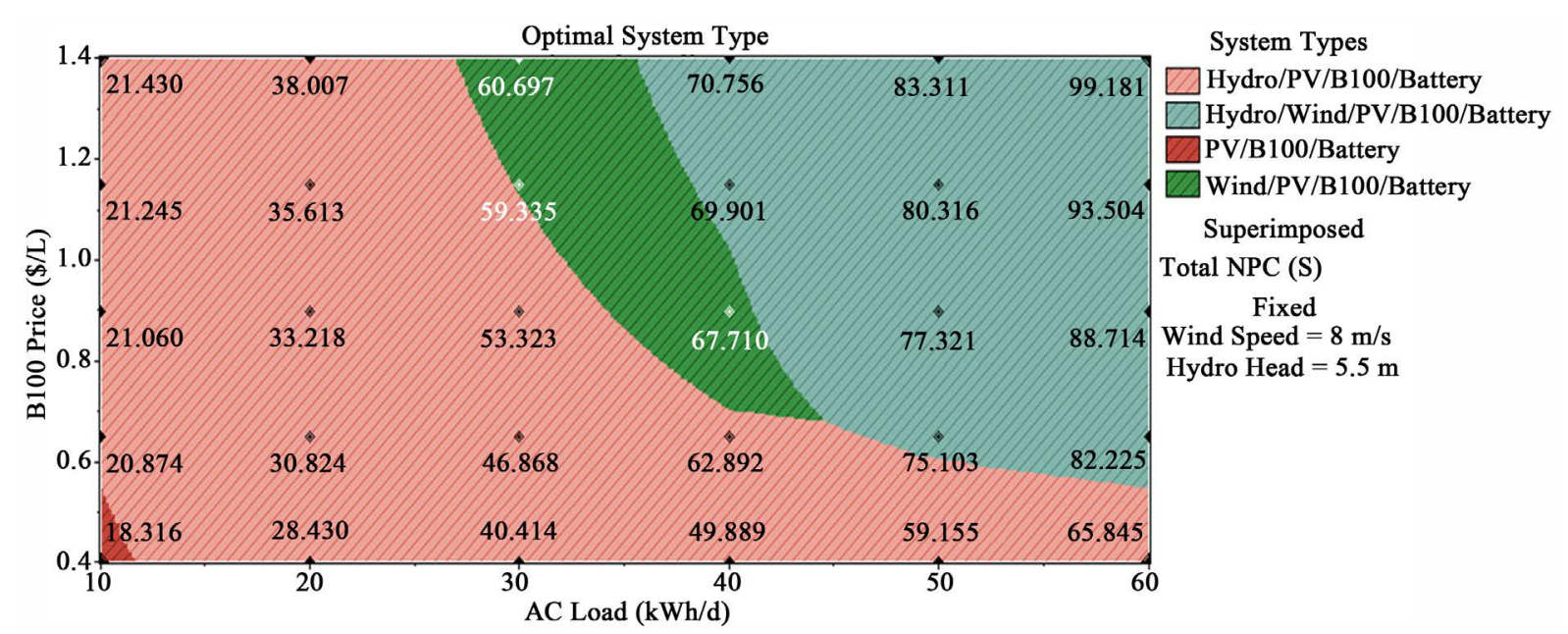

(a)

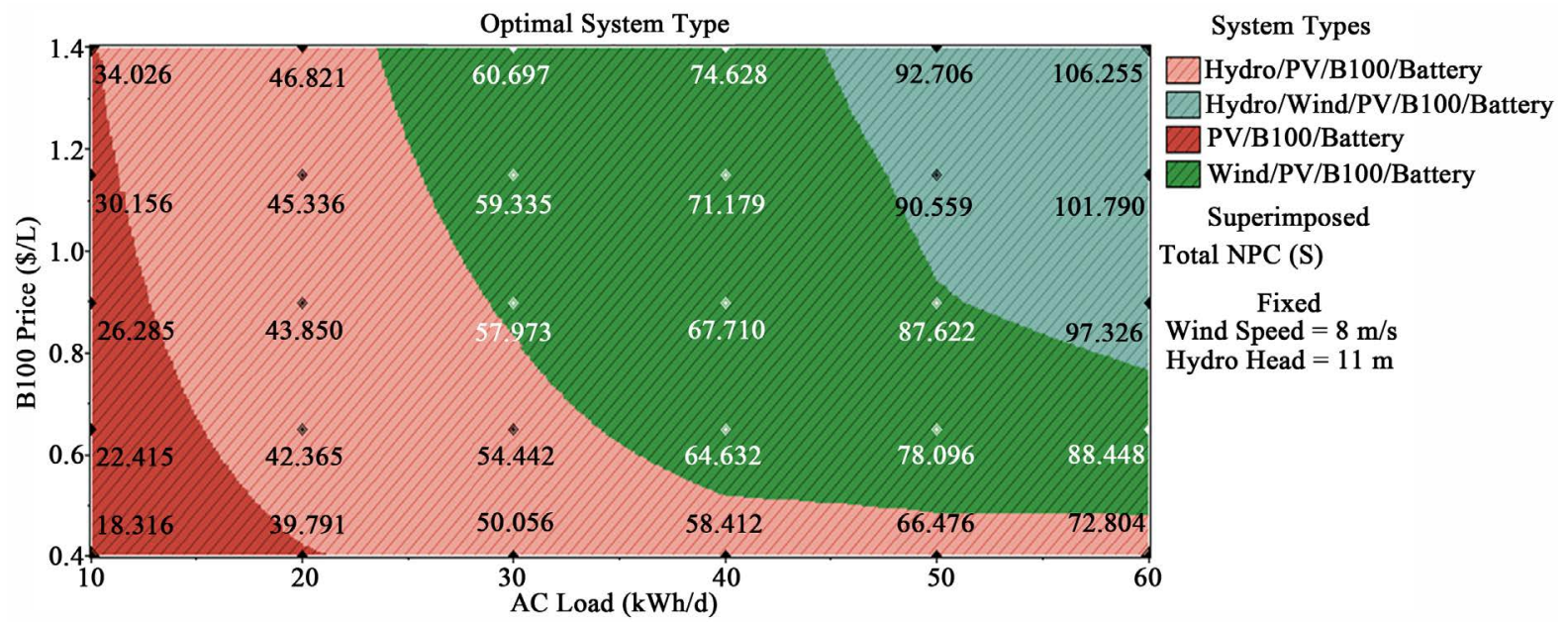

(b)

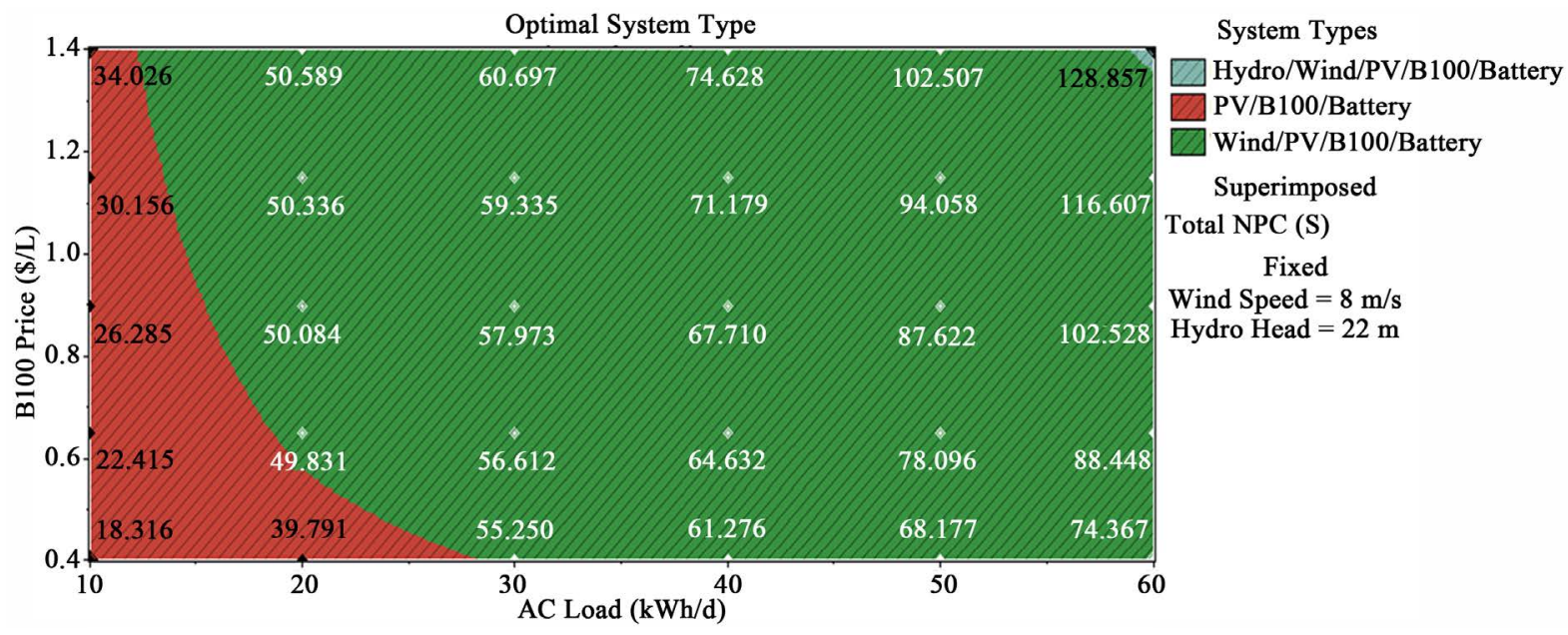

(c)

Figure 15. Optimization space for the system of Figure 8(a), showing biodiesel price as a funciont of AC load for wind speed of $8 \mathrm{~m} / \mathrm{s}$ and (a) one current energy conversion device; (b) two current energy conversion devices; (c) four current energy conversion devices, with values of total net present cost superimposed on graphic. 
equal to $1 \mathrm{~m} / \mathrm{s}$ and for capital costs of USD\$ 4000 per $\cdot \mathrm{kW}$ installed. These values enable the optimization spaces were occupied by a lot of viable solutions including current power plants.

Figure 14(a) shows wind speed as a function of biodiesel price for only one current energy conversion device and AC load of $60 \mathrm{kWh} / \mathrm{d}$, with values of total net present cost superimposed on graphic. A large part of the solutions include a current power plant, with the central part of the optimization space with cost of energy varying between USD \$ 0.280/kWh and USD\$ 0.400/kWh. The solutions without current power plants appear in the upper left corner, in the region in green, corresponding to higher wind speeds and lower biodiesel costs.

Figure 14(b) shows the same results for two current devices. The green region with solutions that do not include plants, advanced in relation to the previous chart. The cost of energy in the central part of the optimization space varies between USD $\$ 0.300 / \mathrm{kWh}$ and USD\$ $0.420 / \mathrm{kWh}$. It can be stated that in this case the rising cost of biodiesel and lower average wind speeds open the way for solutions including current power plants. Figure 14(c) shows the same results for four current devices with green region occupying most of the optimization space.

A comprehensive study on the inclusion of current energy conversion devices in the studied hybrid system should rely on the comprehensive simulation of this system to cover other values of the average current speeds and other multipliers for capital costs, replacement costs and operations and maintenance costs. As already established, this technical note only shows the applicability of Homer for simulation of current power plants, without exhausting this case study taken as an application example.

Figure 15 shows results exactly like the graphs shown in Figure 11(b), Figure 12 and Figure 13. Figure 15(a) shows biodiesel price as a function of AC load for wind speed of $8 \mathrm{~m} / \mathrm{s}$ and one current energy conversion device, with values of total net present cost superimposed on graphic. Again, a large proportion of solutions include current power pants. The green region corresponds to the same type of solution of the previous figure and occupies in this optimization space a relatively small area in an approximately central position.

Figure 15(b) shows the same results for two current devices, indicating a reduction of the number of solutions including current power plant and an increase in the green region. The cost of energy in the central part of this optimization space varies between USD \$ 0.300/kWh and USD\$ 0.420/kWh. Figure 15(c) shows the same results for four current devices, pointing few solutions including current power plants. The cost of energy in the central part of this optimization space varies between USD\$ 0.320/kWh and USD\$ 0.460/kWh.

The number of current energy conversion devices in this model cannot be taken as an optimization variable. Thus, the number of conversion devices is inserted as different eights. So the simulations for these different heights must be repeated and the results compared, in order to determine the optimal number of current devices. This comparison can be improved with the post processing of the data provided by Homer.

The lowest values of the total net present cost, which is the criterion for construction of optimization space,. indicate that solutions with one current energy conversion device are the optimal solutions. Loosening such a requirement, costs of energy obtained with two current energy conversion devices indicate that these solutions can also prove interesting. All optimization spaces in these figures present high renewable energy fraction and failure of energy supply or surplus of energy virtually zero.

\section{Final Remarks}

This technical note described how the software Homer can be used in a simple way for feasibility studies of hybrid systems including current power plants. The Legacy version of Homer software has universal access at no cost. A case study in southern Brazil has shown details of the adaptation of Homer for description of current power plants and its inclusion in a PV wind biodiesel hybrid system already in operation.

Importantly, a feasibility window can be identified with the use of Homer. A window allowing to characterize the initial capital costs and efficiencies necessary to current energy conversion devices for which viable solutions include current power plants. A feasibility window indicates technologies and equipment appropriate to a specific hybrid system.

\section{Acknowledgements}

This work was developed as a part of research activities on renewable energy developed at the Instituto de Pesquisas Hidráulicas, Universidade Federal do Rio Grande do Sul. The authors acknowledge the support received by the institution and the partial support provided by CNPq through scholarships. 


\section{References}

[1] EMEC, The European marine Energy Centre Ltd. (2015) Tidal Devices. www.emec.org.uk/marine-energy/tidal-devices/

[2] Douglas, C.A., Harrison, G.P. and Chick, J.P. (2008) Life Cycle Assessment of the Seagen Marine Current Turbine. Proceedings of the Institution of Mechanical Engineers, Part M: Journal of Engineering for the Maritime Environment, 222, 1-12. http://pim.sagepub.com/content/222/1/1.full.pdf+html

[3] Huxham, G.H., Cochard, S. and Patterson, J. (2012) Experimental Parametric Investigation of an Oscillating Hydrofoil Tidal Stream Energy Converter. Proceedings of the 18th Australasian Fluid Mechanics Conference, Launceston, 3-7 December 2012. http://people.eng.unimelb.edu.au/imarusic/proceedings/18/254\%20-\%20Huxham.pdf

[4] Homer Energy (2009) Software HOMER, Version 2.68 Beta, the Micropower Optimization Model. www.homerenergy.com

[5] Lilienthal, P.D., Lambert, T.W. and Gilman, P. (2011) Getting Started Guide for Homer Legacy (Version 2.68). Homer Energy, Boulder, CO, National Renewable Energy Laboratory (NREL) of the USDOE, Golden, CO, 28 p.

[6] Twidell, J. and Weir, T. (2006) Renewable Energy Resources. 2nd Edition, Taylor and Francis, London.

[7] Bahaj, A.S. (2011) Generating Electricity from the Oceans. Renewable Sustainable Energy Reviews, 15, 3399-3416. http://dx.doi.org/10.1016/j.rser.2011.04.032

[8] Lambert, T.W., Gilman, P. and Lilienthal, P.D. (2005) Micropower System Modeling with Homer. In: Farret, F.A. and Simões, M.G., Eds., Integration of Alternative Sources of Energy, John Wiley \& Sons, Hoboken, 379-418. http://dx.doi.org/10.1002/0471755621.ch15

[9] Lilienthal, P.D., Lambert, T.W. and Gilman, P. (2004) Computer Modeling of Renewable Power Systems. Encyclopedia of Energy, 1, 633-647. http://dx.doi.org/10.1016/b0-12-176480-x/00522-2

[10] Silva, J.S., Beluco, A. and Almeida, L.E.B. (2014) Simulating Ocean Wave Power Plants with Homer. International Journal of Energy and Environment, 5, 619-630. www.ijee.ieefoundation.org/vol5/issue5/IJEE_09_v5n5.pdf

[11] Ponticelli, F.A. and Beluco, A. (2014) Inclusion of Biodiesel and PV Modules in a Wind Diesel Hybrid System Supplying Electrical Loads on a Small Farm. International Journal of Renewable Energy Technology, 5, 239-250.

[12] Caetano Branco Company (2012) Branco Generators Set. www.branco.com.br/us

[13] Cell Energy International (2013) WES 5 Tulipo Wind Turbine. http://cellenergyinternational.co.uk/pdf/WES5_Tulipo_brochure_ds1.pdf

[14] Google Inc. (2013) Google Maps. http://maps.google.com/

[15] Fischer, A., Beluco, A. and Almeida, L.E.S.B. (2013) Preliminary Determination of the Energy Potential of Ocean Currents along the Southern Coast of Brazil. International Journal of Energy and Environment, 4, 879-894. www.ijee.ieefoundation.org/vol4/issue5/IJEE_13_v4n5.pdf 